\title{
New observational insights into the atmospheric circulation over the Euro-Atlantic sector since 1685
}

\author{
Javier Mellado-Cano ${ }^{1,3}$ (D) David Barriopedro ${ }^{2} \cdot$ Ricardo García-Herrera $^{2,3} \cdot$ Ricardo M. Trigo $^{1,4}$
}

Received: 2 September 2018 / Accepted: 26 October 2019 / Published online: 7 November 2019

(c) The Author(s) 2019

\begin{abstract}
Wind direction kept in ships' logbooks is a consolidated but underexploited observational source of relevant climatic information. In this paper, we present four indices of the monthly frequency of wind direction, one for each cardinal direction: Northerly (NI), Easterly (EI), Southerly (SI) and Westerly (WI), based on daily wind direction observations taken aboard ships over the English Channel. These Directional Indices (DIs) are the longest observational record of atmospheric circulation to date at the daily scale, covering the 1685-2014 period. DIs anomalies are associated with near-surface climatic signals over large areas of Europe in all seasons, with zonal indices (WI and EI) and meridional indices (NI and SI) often affecting different regions. Statistical models including all DIs are able to explain a considerable amount of European climate variability, in most cases higher than that accounted for by the North Atlantic Oscillation. As such, the DIs are able to reproduce the known European climatic history and provide new insights of certain episodes from monthly to multi-decadal time scales such as the warm winter decade of 1730-1739 or the extremely cold 1902 summer. The DIs show the potential to better constrain the atmospheric circulation response to external forcings and its associated anomalies. In particular, we provide first observational evidences of all year-round atmospheric circulation signals following the strongest tropical volcanic eruptions of the last three centuries. These signatures are more complex than previously thought and suggest that the well-reported winter warming and summer cooling cannot be simply interpreted in terms of changes in zonality.
\end{abstract}

Keywords Atmospheric circulation index $\cdot$ Climate variability $\cdot$ Early instrumental data $\cdot$ Ships' logbooks $\cdot$ North Atlantic Oscillation

Electronic supplementary material The online version of this article (https://doi.org/10.1007/s00382-019-05029-z) contains supplementary material, which is available to authorized users.

Javier Mellado-Cano

jmcano@fc.ul.pt; jmellado@ucm.es

1 Instituto Dom Luiz, Faculdade de Ciências, Universidade de Lisboa, Lisbon, Portugal

2 Instituto de Geociencias (IGEO), Consejo Superior de Investigaciones Cienctíficas-Universidad Complutense de Madrid (CSIC-UCM), Madrid, Spain

3 Departamento de Física de la Tierra y Astrofísica, Facultad de Ciencias Físicas, Universidad Complutense de Madrid, 28040 Madrid, Spain

4 Departamento de Meteorologia, Universidade Federal do Rio de Janeiro, Rio de Janeiro 21941-916, Brazil

\section{Introduction}

Ships' logbooks are a relevant and consolidated source of observational data, yielding direct observations of wind direction, wind force and weather for the world's oceans and seas (see García-Herrera et al. 2018 for a review). Nonetheless, they have been scarcely exploited to reconstruct climate variability in the past. Among all the information contained in ships' logbooks, wind direction can be considered an instrumental observation, as it has been measured with a compass for centuries. During the last decade several studies have shown that daily wind direction taken aboard ships is a powerful tool to characterize the atmospheric circulation in different areas of the world (Barriopedro et al. 2014; Ayre et al. 2015; Gallego et al. 2015; Vega et al. 2018). This task was frequently carried out by synthesizing the daily information on monthly indices that provide the recurrence of the wind from a given direction (García-Herrera et al. 2018 and references therein). 
Wind directional indices have allowed the characterization of regional monsoon systems and the associated precipitation. For example, the African South Westerly Index, based on wind direction observations over the West African coast, is a valuable indicator of the Western African Monsoon and of the precipitation in the Sahel (Gallego et al. 2015). A Western Circulation Index (Ordonez et al. 2016) accounts for the Indian Summer Monsoon onset over Kerala, which is the most important climatological event in the region. Vega et al. (2018) characterized the Western North Pacific Summer Monsoon since 1898 through the use of historical wind direction observations over the eastern coast of China, doubling the length of available indices based on reanalyses. A similar index has shown a steady enhancement of the Australian Monsoon since the early 19th century (Gallego et al. 2017).

Wind-based indices have also been recently employed to characterize more local circulations, such as those associated to the Etesian winds in the Mediterranean (GómezDelgado et al. 2018), and long-term climate fluctuations over targeted and poorly sampled areas of the globe, such as the Arctic (Ayre et al. 2015). In the Atlantic region, Wheeler et al. (2009) used ships' logbooks from the Royal Navy to study the atmospheric circulation over the English Channel between 1685 and 1750, thus providing a detailed analysis for the end of the Little Ice Age (LIA, 1400-1850). Inspired by this study, Barriopedro et al. (2014) developed the Westerly Index (WI), which measures the frequency of days in the month with westerly wind over the English Channel since 1685 until 2008. The WI showed significant temperature and precipitation signals over Europe, providing additional and complementary information to the more stablished North Atlantic Oscillation (NAO) indices. Indeed, Vicente-Serrano et al. (2015) found that when the NAO and WI are considered jointly, other European circulation indices do not add significant information to explain the variability of drought severity in most of Europe.

All these studies stress the value of ships' logbooks as a reliable source of climate variability and associated atmospheric circulation information. However, many of them are based on unidirectional wind indices. For example, despite its unquestionable value, the WI provides limited skill to capture the atmospheric circulation over the eastern Atlantic, partially because it disregards the information contained in other wind directions. In fact, a decline in the frequency of westerlies should be compensated by increases in other wind directions, each causing different impacts. Accounting for wind anomalies in directions other than the westerly can thus bring a substantial step forward into the characterization of the Euro-Atlantic atmospheric circulation through the last centuries. Recently, Mellado-Cano et al. (2018) used wind roses to uncover substantial decadal variability of the atmospheric circulation during the Late Maunder Minimum
(LMM, ca. 1685-1715), which had been largely unnoticed in the literature (including the WI of Barriopedro et al. 2014).

In this paper, we exploit ships' wind direction records to extend the WI to other cardinal directions, building directional circulation indices over the eastern Atlantic for the period 1685-2014, which covers the transition from the LIA to present. The paper is structured as follows. Section 2 describes the data sources and treatment. In Sect. 3, we present the methodology employed in the construction of the wind directional indices. Section 4 analyzes the climatic signals of each DI separately and their joint information is compared to that of the NAO. The analysis of the time series and the inferred assessment of the European past climate are given in Sect. 5. Section 6 described the impact of tropical volcanic eruptions on the DIs. Finally, in Sect. 7, we summarize the main findings.

\section{Data}

For the construction of the wind indices, two different sources of wind direction observations have been used: the International Comprehensive Ocean-Atmosphere Data Set (ICOADS, version 3.0) for 1850-2014 and archival ships' logbooks (1685-1870) not included in the ICOADS dataset. The oceanic region chosen for this study is the English Channel $\left(10^{\circ} \mathrm{W}-5^{\circ} \mathrm{E}, 48^{\circ} \mathrm{N}-52^{\circ} \mathrm{N}\right)$, which allows us to construct quasi-continuous series for the period 1685-2014 and captures relevant atmospheric phenomena for the European climate (Wheeler et al. 2009; Barriopedro et al. 2014; Kidston et al. 2015; Vicente-Serrano et al. 2015).

To supplement ICOADS records, we used ships' logbooks records from the UK National Archive and the National Maritime Museum, obtaining a total of 74,363 daily observations for the $1685-1870$ period. The collected data include additional abstracted records to those recovered in previous studies (Wheeler et al. 2009; Barriopedro et al. 2014), particularly for the $1830-1870$ period, thus providing a smooth transition to ICOADS. Wind information was found for $97.9 \%$ of the days in the $1685-1870$ period (Fig. 1a). The wind direction recorded in ships' logbooks was measured with a 32-point compass in degrees with respect to the magnetic north and $\sim 11^{\circ}$ resolution. Calm and variable wind situations were also annotated. For each day, only one (the midday) observation was abstracted. These data only required very minor corrections: (1) the change from Julian to Gregorian calendar before 1753 and from nautical to civil day (a $12 \mathrm{~h} \mathrm{lag}$ ); (2) the correction due to the magnetic variation. The latter was applied by using monthly magnetic declination data (in degrees from true north) with $1^{\circ} \times 1^{\circ}$ longitude-latitude resolution over the English Channel from the NOAA National Geophysical Data Center (NGDC, Jackson et al. 2000). The correction was applied 
Fig. 1 a Annual frequency of daily wind direction observations over the English Channel (in observations per year) from ships' logbooks (1685-1870) and ICOADS v3.0 (18502014); b monthly percentage of days with missing data (grey line) during the 1685-2014 period. The black line shows a 12-month running mean (a) Observations in English Channel

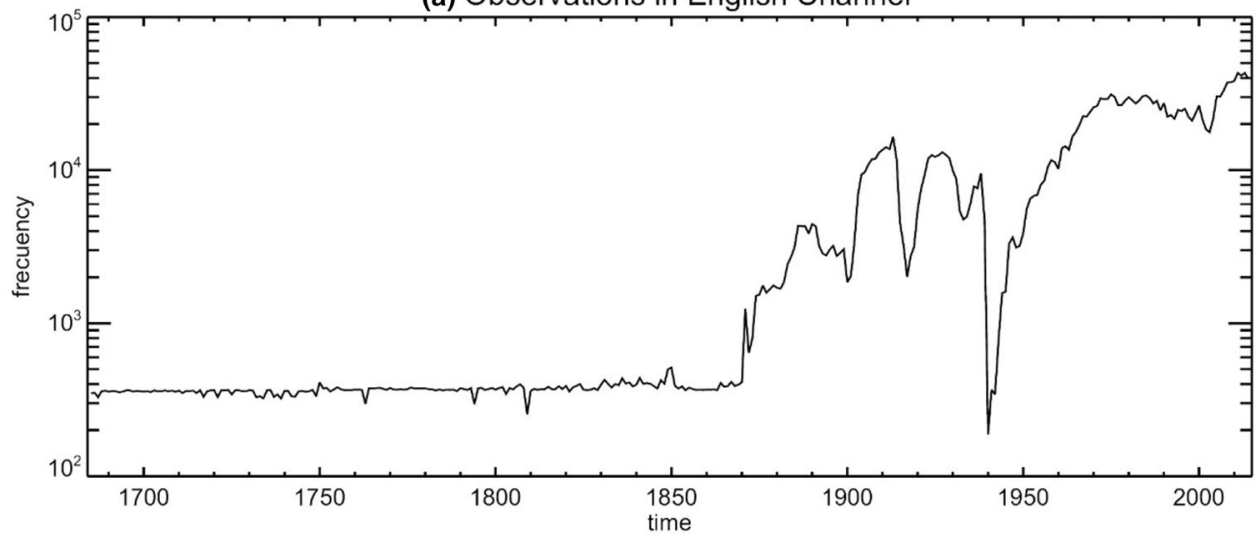

(b) Missing data

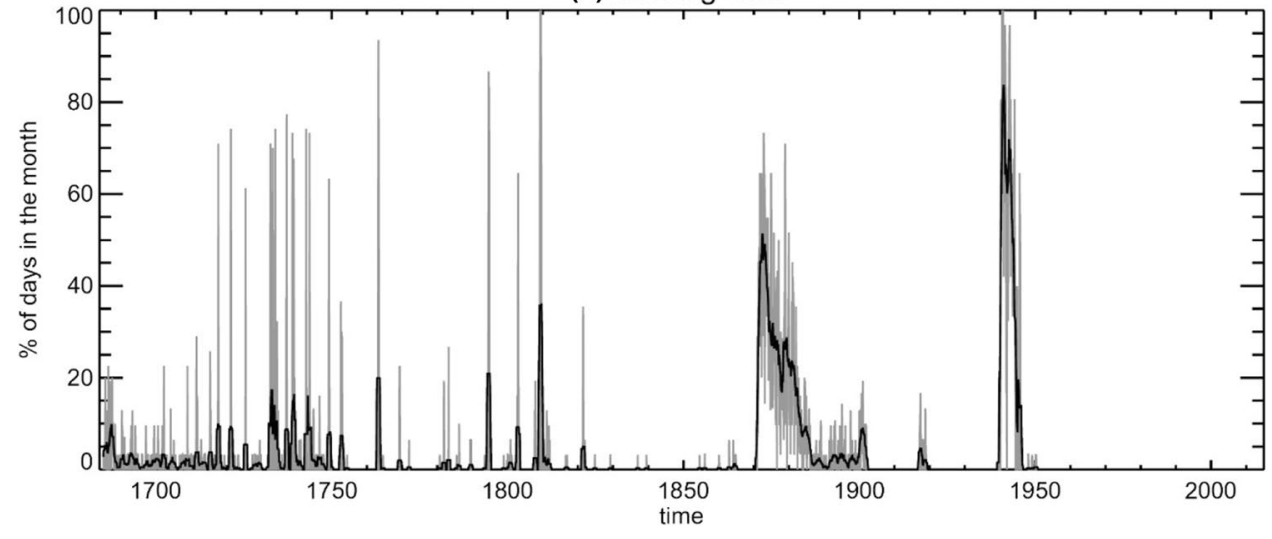

by simply adding the regional mean magnetic declination of the given year and month (Figure S1a in the Supplementary Materials) to all daily compass readings available for that time, with the exception made to calm and variable winds. The reader is referred to Wheeler et al. (2009) and Barriopedro et al. (2014) for additional information on these ships' logbooks and their wind direction records.

On the other hand, ICOADS v3.0 (Freeman et al. 2017) contains $\sim 453$ million records over the globe starting in 1662, with 4,318,330 observations for the English Channel alone (Fig. S1b), although most of them (99.4\%) were confined to the period after 1870 , which prevents deriving continuous series before that time. ICOADS provides surface marine data over the study area from different sources (e.g. buoys, coastal platforms, oceanographic instruments), mainly ships (69.2\%). The frequency of ICOADS records within the English Channel increases with time, showing an abrupt growth in the last part of the analyzed period, largely due to wind observations taken at different times of the day over the same geographical locations. For coherence with the logbooks' observations of the 1685-1870 period, and to avoid biases towards oversampled points, we only selected the ICOADS observations taken from ships and at the closest time to 12:00 UTC. Similar to ships' logbooks, ICOADs observations over open sea were preferred to avoid orographic effects in seaports. After merging both datasets, the resulting database displays good temporal coverage, except for years around 1875 and the WWII period (Fig. 1b), with $96.0 \%$ of the days in the 1685-2014 period containing at least one wind observation over the English Channel (Fig. 1a).

\section{Methodology}

Our objective is to compute wind indices for the four cardinal directions, measuring the recurrence of each principal wind direction in a given month. To do so, the first step was to assign the prevalent direction of each day to one of the four quadrants. Following the criteria adopted by Wheeler et al. (2009) and Barriopedro et al. (2014), we consider an easterly wind day as that with wind blowing from the (45, $135)^{\circ} \mathrm{N}$ sector. Bearing in mind that there are often several wind observations per day, we adopted a procedure similar to Barriopedro et al. (2014). Accordingly, when only one daily observation was available, the day was classified taking the wind direction $d$ of that single observation (with $d$ denoting northerly, easterly, southerly or westerly). If several observations were available, we demanded a minimum percentage $p_{d}$ (with respect to the total number of observations 
of that day) with $d$ wind direction in order to classify it as a $d$-wind day. To determine the optimal $p_{d}$ thresholds, we adapted the unidirectional procedure described in Barriopedro et al. (2014) for the WI to the four cardinal directions (see Supplementary Materials and Figure S2). This approach minimizes the discrepancies derived from the time-varying number of daily observations. As a result, different (but close) $p_{d}$ thresholds were adopted for each wind direction, namely $36 \%, 44 \%, 37 \%$ and $45 \%$ for northerly, easterly, southerly and westerly winds, respectively. Using this methodology, the number of unclassified days was low $(<6 \%)$, and days simultaneously classified in two wind directions were equally rare and treated by choosing the most likely one $(<4 \%)$ (see Supplementary Materials).

Once all days were classified, a monthly index was defined for each direction as the percentage of days per month with wind blowing from that direction. The resulting Northerly (NI), Easterly (EI), Southerly (SI) and Westerly (WI) indices are overall referred to as the Directional Indices (DIs). The monthly percentage values of the DIs series are computed with respect to the total number of days of each month with at least one wind observation (calm and variable winds are excluded). They were considered meaningful when at least two thirds of the days in the month were classified in one wind direction (otherwise, the month was labelled as missing). Based on the total number of wind records available in the month we also quantified the uncertainty of the DIs series (Gallego et al. 2015). The method accounts for potential undersampling issues derived from insufficient number and/or coverage of observations. The magnitude of the uncertainties is similar for all DIs series and decreases with time up to a minimum of around $\pm 10 \%$, which is related to the intrinsic wind direction variability within the English Channel (see Supplementary Materials and Figure S3 for further information).

There are potential sources of inhomogeneity unrelated to climate that could affect the DIs. They include changes in the instrument and/or observational procedure, as well as in the density and location of the available observations. The former is not expected to cause artificial effects on the DIs, since wind direction was always recorded with a compass of higher resolution than that required for the DIs and following the same observational standards (Wheeler et al. 2009). Regarding the latter, undesired effects have been minimized during the methodological construction of the DIs and are partially accounted for by the uncertainty of the DIs. To further explore this issue, a homogeneity test was applied to each DI series. The lack of any reference series hampers the use of standard homogeneity tests that are often employed to detect shifts in the time series unrelated to real climate variations (e.g. Alexandersson's test) (Alexandersson 1986; Alexandersson and Moberg 1997). We used an absolute test instead, which can be applied to each DI separately (Yozgatligil and Yazici 2015), allowing us to identify common changes in all series, herein interpreted as inhomogeneities in the underlying data. The test is based on the Schwarz criterion (Schwarz 1978), which provides the most likely number and location of shifts in the mean by using intervals of different length in running windows. The results indicate different locations for the potential breakpoints of each DI series. For the SI, we detected a suspicious change point in 1853 , which is close to the shift from ships' logbooks to ICOADS observations. However, it was not detected in the other DIs and there was no additional evidence suggesting real inhomogeneities at that time. Therefore, we conclude that changes in the number and/or in the data source do not introduce artificial shifts in the DIs series.

\section{The impact of the Dls on the European climate}

The annual mean values of the DIs are $19.1 \%, 18.7 \%, 21.5 \%$ and $34.6 \%$ for NI, EI, SI and WI, respectively, indicating the predominance in the region of westerly and southerly winds. The WI presents a more pronounced annual cycle (Figure S4), with a maximum in summer. This is due to the seasonal shift of the atmospheric action centers in the North Atlantic, which are tilted in the SE-NW direction throughout the year, except in summer, when they are located along the same meridian. The westerly veering of the winds during summer causes a decline in the frequency of the other components, affecting the seasonality of the SI, which presents a maximum (minimum) during winter (summer). Similar results are obtained using 8-point wind roses (i.e. eight wind directional indices), derived as in Mellado-Cano et al. (2018). In particular, the frequency of days with wind blowing from the SW and NE quadrants are higher than those corresponding to wind directions in the NW and SE sectors, respectively (Figure S5), reflecting the characteristic tilt of the eddydriven jet stream (Woollings et al. 2010). For simplicity, the following analyses will focus on the four DIs, which provide a manageable number of indices.

The prevalence of westerlies and southerlies wind regimes is also in agreement with the recently developed catalogue of Lamb Weather Types (LWTs) over the British Isles by Delaygue et al. (2019). Although the DIs are significantly correlated with the seasonal frequency of their corresponding directional LWTs over the overlapping period (e.g. $r=[0.31-0.55]$ for the winter series of 1781-1996, $\mathrm{p}<0.01$ ), a straightforward comparison is hampered by the different number of classes considered (seven indices in the LWTs vs four DIs). To address this issue, we computed different combinations of the LWTs (by aggregating their days in new hybrid LWTs) and searched for the combinations 
that are more consistent with the DIs. The correlations of the DIs with their corresponding LWTs (herein referred to as $\mathrm{N}, \mathrm{S}, \mathrm{E}$ and $\mathrm{W}$ ) improve when the days of non-cardinal LWTs (Cyclonic (C), Anticyclonic (A) and NW) are also considered (see Table S1). In particular, the EI, SI, WI and NI exhibit the highest correlation coefficients with $\mathrm{E}+\mathrm{A}$, $\mathrm{S}+\mathrm{C}, \mathrm{W}+\mathrm{NW}$ and N LWTs, respectively. The inclusion of $\mathrm{C}$ in the hybrid W + NW LWT further increases the correlation with the WI, but the improvement is substantially lower than that obtained when $\mathrm{C}$ days are added to those of $\mathrm{S}$. Thus, to avoid double counting of $\mathrm{C}$ days in two different hybrid LWTs, they were only aggregated to $\mathrm{S}$ days. Overall, the relationships between the DIs and the selected hybrid LWTs are slightly stronger for the zonal (WI and EI) than for the meridional (NI and SI) DIs (Table S1). In addition, the correlations are non-stationary, with a tendency for a generalized decrease back in time, as well as several minima at different times, depending on the considered DI (not shown). The progressive backward loss of explained variance may be due to the decrease in the number (and arguably the quality) of available observations, as well as to methodological issues (i.e. correlations are affected by the number of unclassified days, which substantially increases before the 20th century in the LWT approach). On the other hand, periods of weakened (not necessarily non-significant) correlations could reflect issues in one or both catalogues, or temporary non-stationary relationships. In this sense, Barriopedro et al. (2014) found several common decoupling periods between the WI and other circulation indices, which were interpreted as changes in the location and/or intensity of the North Atlantic action centers. Some (but not all) of these periods can also be inferred from the comparison with LWTs (e.g. the second half of the 19th century), but we also identify decoupling intervals with some of the LWTs that were not detected therein (e.g. the beginning of the 19th century). Unfortunately, the exact causes of disagreement cannot be discerned in a straightforward way and deserve further research, which is out of the scope of this paper. For further comparisons of the DIs with other observational indices of the atmospheric circulation over the Euro-Atlantic sector (e.g. the Paris-London index, Cornes et al. 2013) the reader is referred to Barriopedro et al. (2014) and MelladoCano et al. (2019), where a detailed assessment of the DIs as potential indicators of the NAO and the East Atlantic (EA) pattern is provided.

Before exploring the DIs series for the 1685-2014 period, we analyzed their signatures on Euro-Atlantic climate variability in order to better understand the climate implications during periods of anomalous DIs, which will be described in the following section. We used monthly near surface temperature from the CRU TS v3.23 database of the Climate Research Unit (Harris et al. 2014) and total monthly precipitation from the Global Precipitation Climatology Centre
(GPCC, Schamm et al. 2014). Both databases are provided on a grid of $1^{\circ} \times 1^{\circ}$ longitude-latitude over land and cover the period 1901-2014. To interpret the temperature and precipitation anomalies, the following variables were also computed for that period by using daily mean fields of geopotential height, temperature, humidity, and zonal and meridional wind at different pressure levels and $2^{\circ} \times 2^{\circ}$ resolution from the 20th Century Reanalysis V2c (Compo et al. 2011): (1) the vertically integrated moisture transport through the 1000-500 hPa layer; (2) the moisture convergence between 1000 and $500 \mathrm{hPa}$; (3) temperature advection at different pressure levels and; (4) the storm-tracks, defined as the standard deviation of the high-pass filtered (2-7 days) geopotential height at $500 \mathrm{hPa}$. The 20th Century Reanalysis assimilates only surface pressure observations, which are expected to be related to the DIs, and hence it provides a state of the atmosphere that is compatible with them.

The relationship of DIs with the Euro-Atlantic climate variability has been assessed on seasonal scales for the period 1901-2014, with winter and summer denoting December-to-February and June-to-August, respectively. For each season and DI we identified the years with positive and negative phases, defined from seasonal-mean DI values above 1 and below - 1 standard deviation (SD), respectively. This provides a balanced and sufficient number of cases, from which we constructed DI-based composites for each phase, and their difference. The composites have been scaled, i.e. multiplied by the mean square root of the sample size and divided by the standard deviation of the sample. The resulting variable is dimensionless but provides a more robust signal than unscaled composites (Brown and Hall 1999; Küttel et al. 2011). The significance of the composite difference was calculated for each grid point using a bootstrap test with 1000 iterations, in which the same number of years as in the composites was selected randomly from the 1901-2014 period. The difference is statistically significant at the $90 \%$ confidence level if it is higher (lower) than the 95th (5th) percentile of its random distribution.

Figures 2 and 3 show the scaled composite differences of temperature-related and precipitation-related variables, respectively, along with the associated atmospheric circulation for each DI. For brevity, we only show the composites for winter and summer (see the results for spring and autumn in Figures S6 and S7 of the Supplementary Materials). The results show nearly opposite signals for the zonal indices in both temperature and precipitation, and the same behavior is observed for the meridional indices. Overall, zonal DIs tend to show larger anomalies and/or affect larger areas of northern and central Europe than meridional DIs, due to their more prominent effect on temperature and moisture advection (shown by arrows and hatching in Figs. 2, 3, respectively). In spite of this, it is important to note that the signatures of zonal and meridional DIs are 
Fig. 2 Winter (a-d) and summer $(\mathbf{e}-\mathbf{h})$ differences between scaled anomaly composites for high (>1 SD) and low (<- $1 \mathrm{SD})$ DIs. The following variables are shown: geopotential height at $500 \mathrm{hPa}$ (Z500, contours), land near-surface temperature (shading), $500 \mathrm{hPa}$ wind (arrows) and $500 \mathrm{hPa}$ temperature advection (hatching). All units are dimensionless. Solid (dashed) contours represent positive (negative) values, with thick lines indicating significant differences from climatology at $\mathrm{p}<0.1$. Only temperature differences that are significant at $\mathrm{p}<0.1$ are shown. Cross-hatched areas with lines orientated $45^{\circ} \%-45^{\circ}$ from the east indicate significant $(\mathrm{p}<0.1)$ warm/cold temperature advection. The size of the arrows is proportional to the magnitude of the $500 \mathrm{hPa}$ wind anomaly (a reference value is shown in the bottom right corner of each panel). For better readability, hatched areas (arrows) are only displayed over land (ocean). Numbers in the left bottom corner of each panel represent the number of cases employed in the composite for high/low DIs. Significance is assessed with a 1000-trial bootstrap test (a) DJF NI Temp

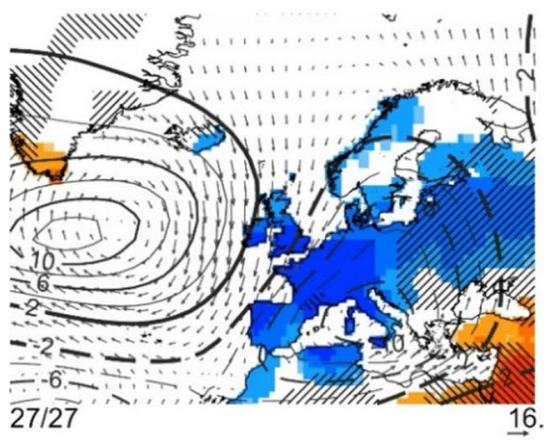

(b) DJF EI Temp

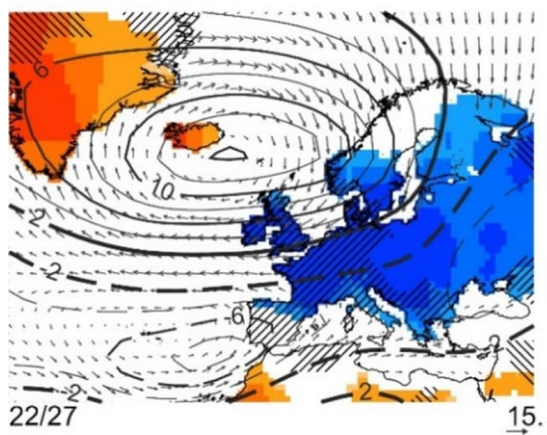

(c) DJF SI Temp

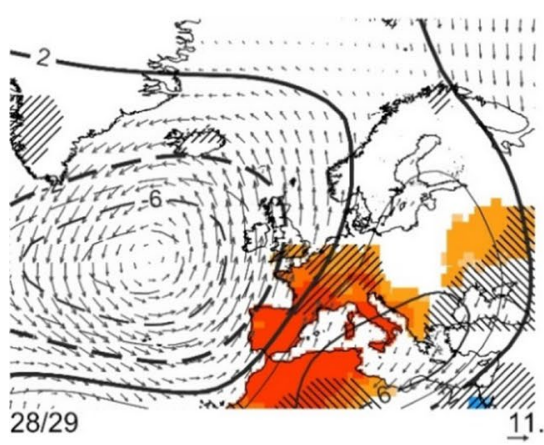

(d) DJF WI Temp

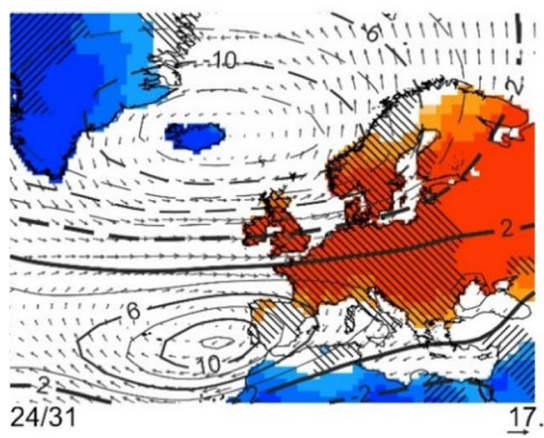

(e) JJA NI Temp

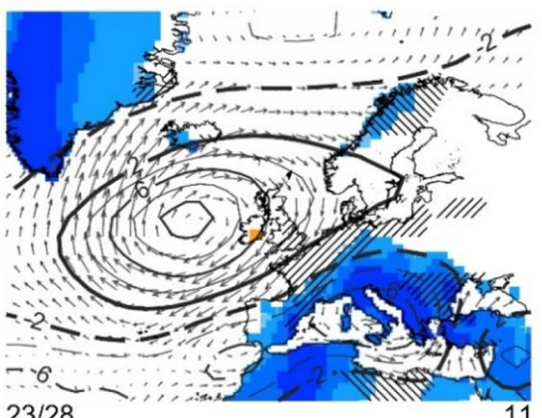

(f) JJA El Temp

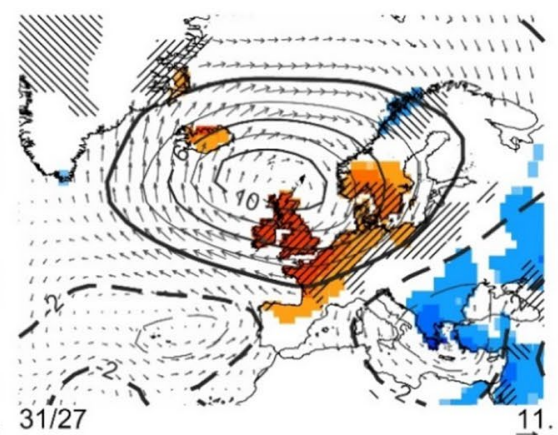

(g) JJA SI Temp

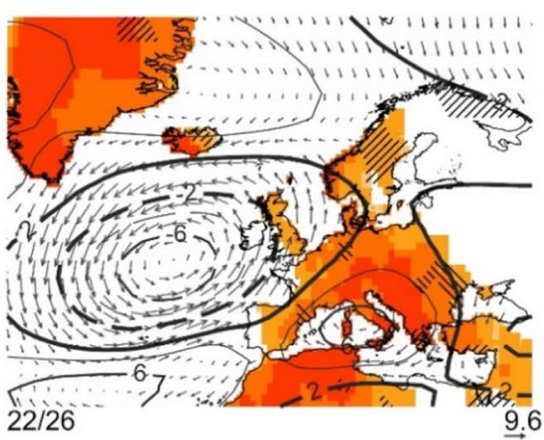

(h) JJA WI Temp

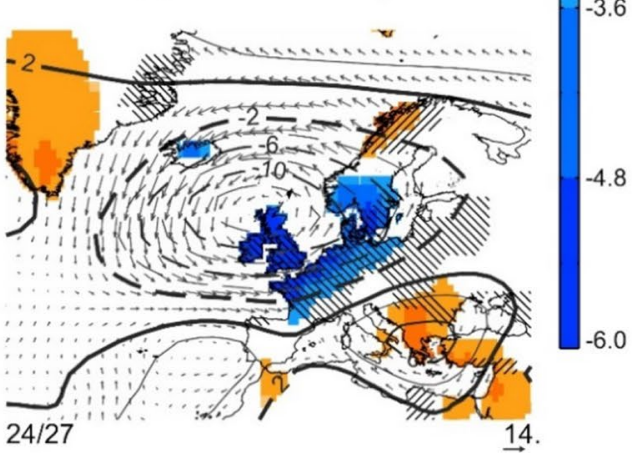

spatially complementary all year-round. Regarding the seasonal impacts, the largest signals are obtained in winter (Figs. 2a-d, 3a-d), when near-surface responses are strongly controlled by the dynamics (Vautard and Yiou 2009). The temperature responses vary seasonally, being qualitatively similar within the cold (winter and autumn, Fig. 2a-d, Fig. S6e-h) and warm (spring and summer, Figs. S6a-d, 2e-h) half of the year. In particular, the temperature signal associated with anomalous zonal winds in winter (Fig. 2b, d) reverses in summer (Fig. 2f, h), despite the smaller spatial 
Fig. 3 As Fig. 2 but for the following variables: storm tracks (2-5 high pass filtered Z500 variance, contours), land precipitation (shading), 1000$500 \mathrm{hPa}$ vertically integrated moisture transport (arrows) and 1000-500 hPa moisture convergence (hatching). All units are dimensionless. Solid (dashed) contours represent positive (negative) values, with thick lines indicating significant differences from climatology at $\mathrm{p}<0.1$. Only precipitation differences that are significant at $\mathrm{p}<0.1$ are shown and gridpoints with climatological mean precipitation below $10 \mathrm{~mm}$ are omitted. Cross-hatched areas with lines orientated $45^{\circ} /-45^{\circ}$ from the east indicate significant $(\mathrm{p}<0.1)$ moisture divergence/convergence. The size of the arrows is proportional to the magnitude of the moisture transport anomaly (a reference value is shown in the bottom right corner of each panel). For better readability, hatched areas (arrows) are only displayed over land (ocean). Numbers in the left bottom corner of each panel represent the number of cases employed in the composite for high/low DIs. Significance is assessed with a 1000-trial bootstrap test (a) DJF NI Prec

(e) JJA NI Prec

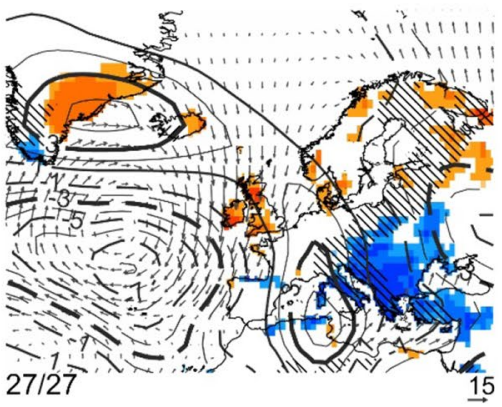

(b) DJF EI Prec

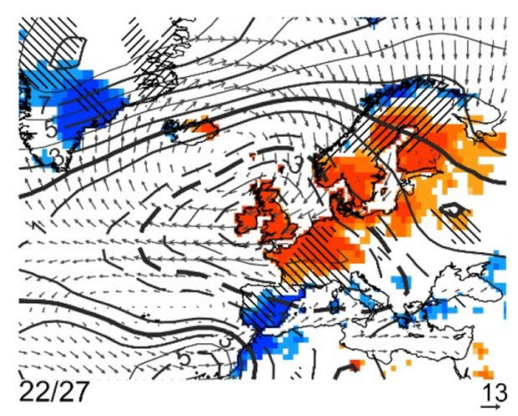

(c) DJF SI Prec

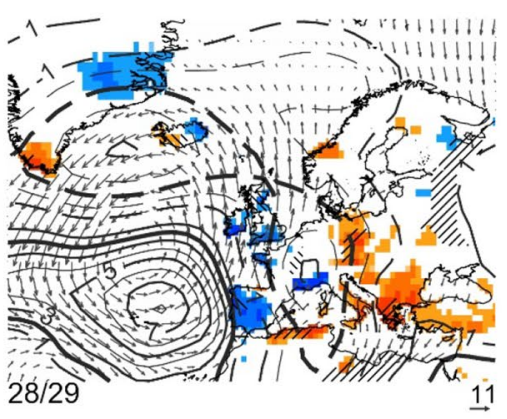

(d) DJF WI Prec

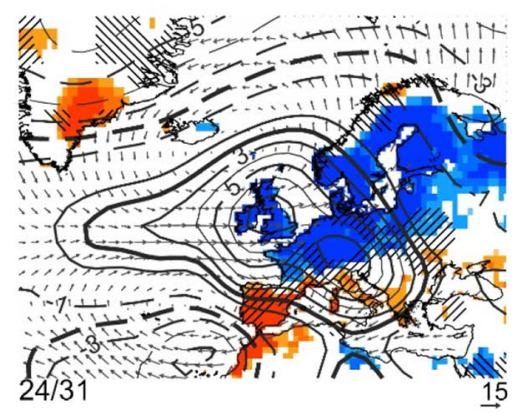

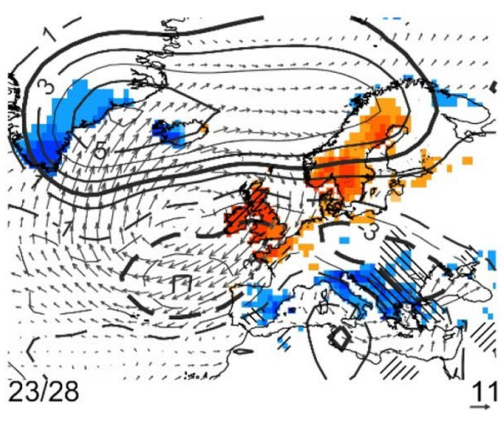

(f) JJA EI Prec

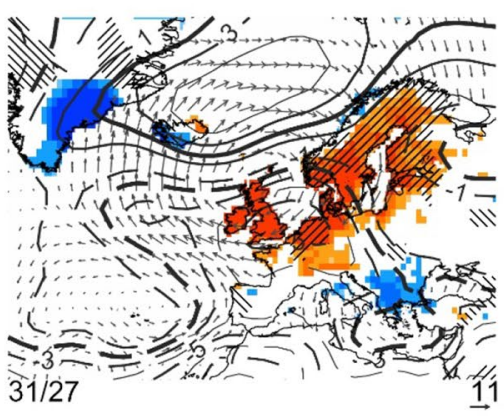

(g) JJA SI Prec

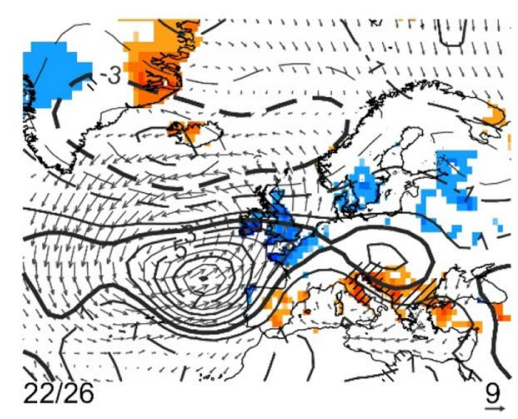

(h) JJA WI Prec

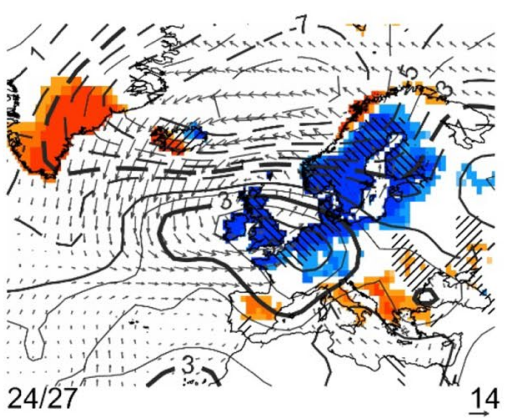

6.00

4.80

3.60 scale anomalies observed in the latter. These temperature signals cannot be fully interpreted as changes in thermal advection, suggesting an additional role of other processes (e.g. radiative fluxes; see Barriopedro et al. 2014). On the contrary, the precipitation responses show a more similar spatial pattern in all seasons (Figs. 3, S7), indicating a major 
role of the wind direction in modulating moisture advection and convergence throughout the year.

Focusing now on the atmospheric circulation, the results show that the DIs anomalies reflect a reorganization of air masses on large spatial scales, embracing the whole EuroAtlantic sector (contours in Figs. 2, 3), which explains to large extent their associated impacts over large areas of Europe. Enhanced westerlies show a meridional dipolar pattern in geopotential height, with negative anomalies at higher latitudes and positive ones in subtropical regions (Fig. 2d, contours) as well as increased storm-track activity affecting most of northwestern and central Europe (Fig. 3d, contours). These patterns resemble the positive phase of the NAO (Trigo et al. 2002) and are nearly opposite to those found for persistent easterlies (Figs. 2b, 3b). In summer, the anomaly centers in geopotential height associated with WI and EI tend to shift equatorward and become spatially more confined (Fig. 2f, h), still resembling the high-summer NAO (Bladé et al. 2012). In fact, WI and EI are significantly correlated with independent NAO indices for the period 1901-2014, such as the winter NAO index of Jones et al. (1997) $\left(\mathrm{r}_{\mathrm{WI}}=0.73\right.$ and $\mathrm{r}_{\mathrm{EI}}=0.60$, both $\left.\mathrm{p}<0.01\right)$, and the summer NAO index of Folland et al. (2009) $\left(r_{\mathrm{WI}}=0.63\right.$ and $r_{\mathrm{EI}}=0.43$, both $\left.\mathrm{p}<0.01\right)$. In spite of this, the DIs and the NAO are able to capture complementary aspects of the circulation and therefore their associated impacts and skills as predictors can show differences, as shown later. On the other hand, the meridional indices are controlled by a zonally oriented dipolar pattern in geopotential height, largely dominated by an anomaly center over the mid latitudes of the Atlantic Ocean (i.e. south of the main axis of the storm tracks, Fig. 2a, c). As such, their largest impacts are recorded in temperature, with enhanced northerlies being associated to high pressure systems over the Atlantic that cause widespread cooling over Europe. On the contrary, an increased frequency of southerlies is associated with Atlantic low pressure systems, favoring warm conditions over Europe. During summer (Fig. 2e, g), the dominant anomaly center in geopotential height shifts towards Europe and stretches meridionally, affecting the spatial extension of the surface anomalies. While the zonal DIs show similarities with the NAO, the winter circulation anomalies associated with the meridional DIs resemble the East Atlantic (EA) pattern (Wallace and Gutzler 1981; Barnston and Livezey 1987). For a more detailed comparison of the DIs with the main patterns of atmospheric circulation variability over the EuroAtlantic sector, the reader is referred to Mellado-Cano et al. (2019).

The distinct spatial signatures of the zonal and meridional DIs stresses the added value of integrating their information. A good example is the hot summer of 2003 (e.g. García-Herrera et al. 2010; Barriopedro et al. 2011), for which the standardized DIs indicate the dominance of southerly and easterly winds $\left(N I_{J J A}(2003)=-0.68 ; E I_{J J A}(2003)=0.83 ; S I_{J J A}(2003)\right.$ $\left.=0.31 ; W I_{J J A}(2003)=-0.60\right)$ both related to warming in southeastern and northwestern Europe, respectively. Another example can be found during the winter period 1960-1990, characterized by positive phases of the NAO (e.g. Pinto and Raible 2012; Hanna et al. 2016). The DIs confirm the prevalence of WI over EI but also large SI values. Precisely, the appearance of this southern circulation involves changes in the geographical location of the North Atlantic action centers, adding evidence to the recent shift of the NAO dipole reported in other studies (e.g. Vicente-Serrano and LópezMoreno 2008).

Despite the complementary signals of zonal and meridional DIs, the results also indicate some redundancy among them. By construction, the sum of the DIs is constant, and therefore enhanced westerlies (northerlies) tend to be associated with reduced easterlies (southerlies), and vice versa, leading to certain degree of collinearity among them, as further described below. To account for this, we used a Stepwise Regression Model (SRM) to find the combination of DIs that best explains the dependent variable (either temperature or precipitation). For each gridpoint, the optimal combination of the DIs was generated step by step, proceeding forwards and backwards (i.e. adding and removing explanatory variables). The resulting model was tested with a Fisher's test based on the sum of the residual squares, retaining only the DIs (if any) that significantly improve the explained variance at the $90 \%$ confidence level (Wilks 2006). Figure 4 shows the best two predictors of temperature (first two columns) and precipitation (last two columns) for each season (rows). The analysis reveals that in most of Europe there is always at least one DI (and often no more than two DIs) explaining a significant fraction of variance of the dependent variable. In terms of spatial extension, DIs are more skillful indicators in winter (Fig. 4, first row) than in the rest of the year, and of temperature (Fig. 4a-h) than precipitation (Fig. 4i-p) anomalies, whose signal is more spatially fragmented and commonly well explained by one DI alone. Still, the DIs are able to explain a significant amount of temperature and precipitation variability over large areas of Europe all yearround. Overall, zonal indices tend to be the best predictors of temperature in central Europe (Fig. $4 \mathrm{a}-\mathrm{d}$ ), with the exception of summer, and of precipitation in most of Europe (Fig. 4i-1). In turn, meridional indices are skillful predictors of temperature in western Europe and eastern Mediterranean, and of precipitation in southeastern Europe. We also note that the most skillful combination of DIs can vary seasonally, particularly for temperature. For example, the WI and NI dominate the temperature anomalies over large parts of the continent during winter, spring and autumn (Fig. 4a, b, d), while EI and SI acquire relatively more importance during summer (Fig. 4c). In spite of these seasonal variations, there is some coherence, in the sense that the leading 

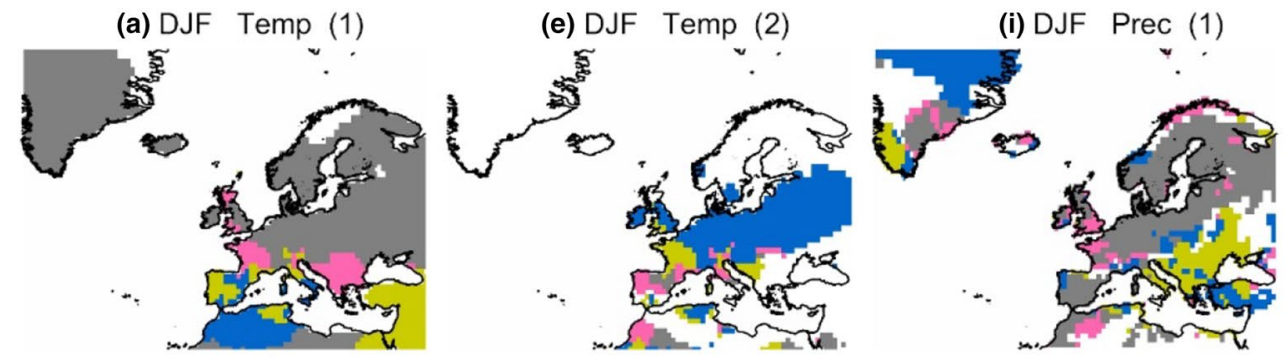

(f) MAM Temp (2)
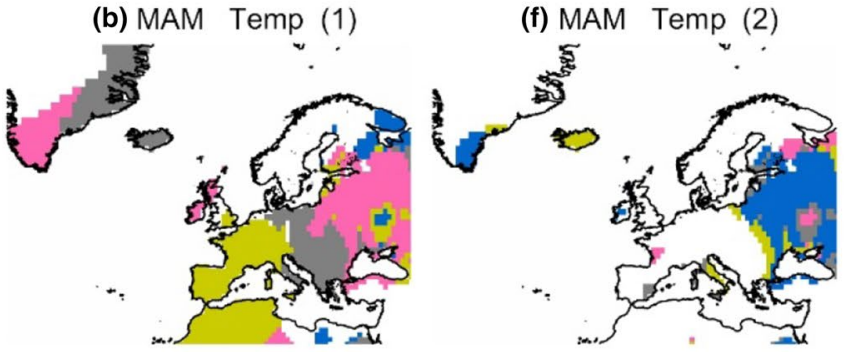

(g) JJA Temp (2)
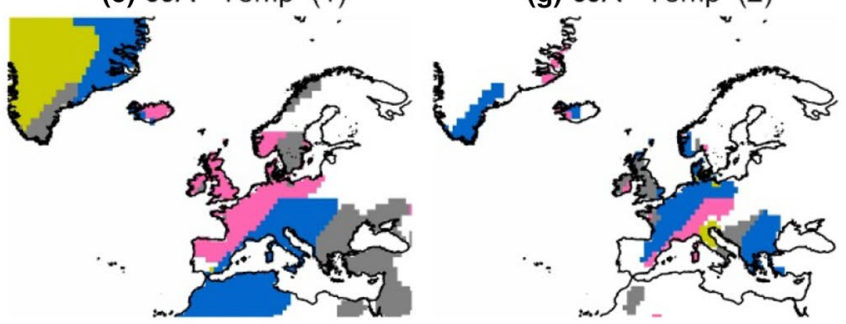

(h) SON Temp (2)

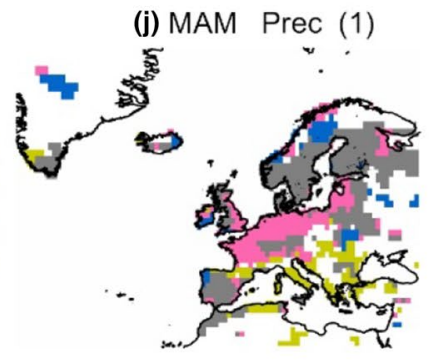

(k) JJA Prec (1) (d) SON Temp (1)

SON Prec (1)

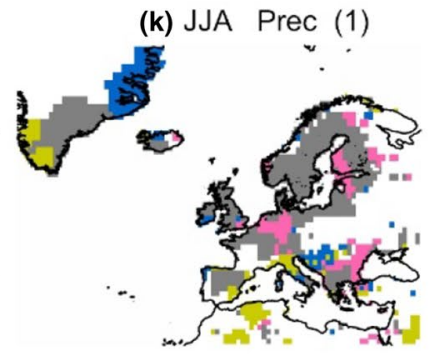

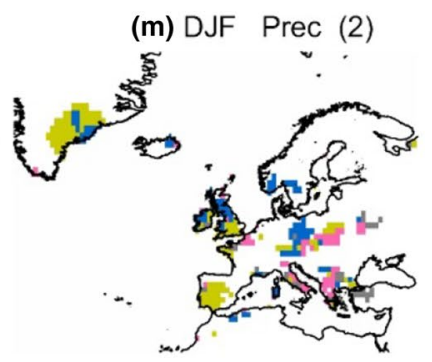

(n) MAM Prec (2)
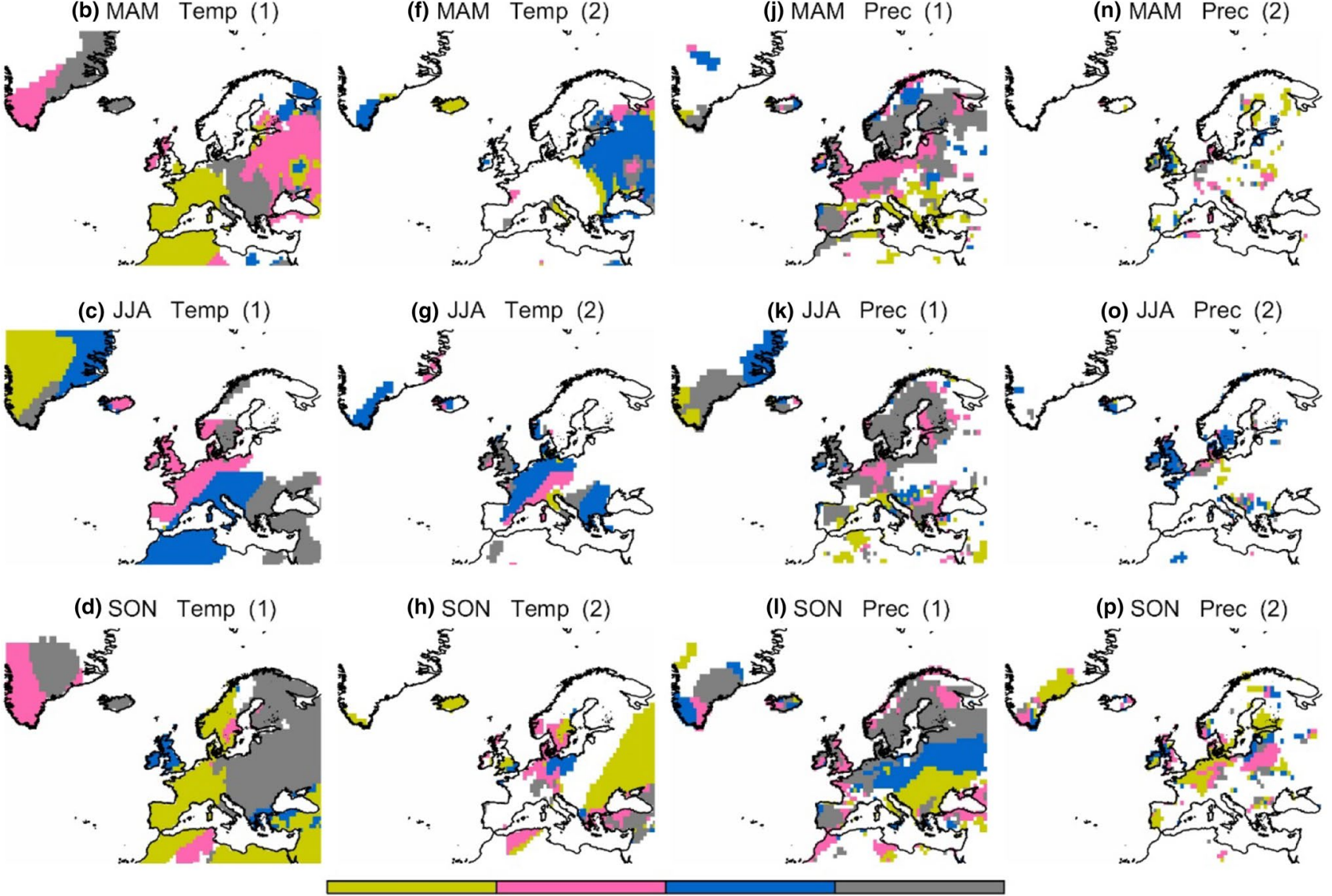

(o) JJA Prec (2)

$\mathrm{NI}$

El

SI

Fig. 4 Stepwise regression model for the period 1901-2014 showing the best DIs predictors of seasonal: $\mathbf{a}-\mathbf{h}$ temperature and; $\mathbf{i}-\mathbf{p}$ precipitation anomalies. The best predictor of each season is shown in panels $\mathbf{a}-\mathbf{d}$ for temperature and $\mathbf{i}-\mathbf{l}$ for precipitation. $\mathbf{e}-\mathbf{h}$ and $\mathbf{m}-\mathbf{p}$ indicate the second best predictor of temperature and precipitation, respec-

DIs of a given season that no longer continue as first European predictors in another, frequently appear instead as second predictors. On the contrary, for precipitation, the WI appears as the dominant DI in large areas of Europe, being selected as first predictor all year-round (Fig. $4 \mathrm{i}-1$ ). This result strengthens the role of maritime air advection as a major driver of precipitation in Europe (Gimeno et al. 2012). However, there are regions and seasons where other DIs are more important, like southeastern Europe, where meridional indices dominate precipitation variability during tively. Rows indicate the respective season from winter (DJF, first row) to autumn (SON, last row). Colors represent the DI: NI (yellow), EI (pink), SI (blue) and WI (grey). White areas show regions where none of the DIs is able to explain a significant amount of variance

the cold seasons (Fig. 4i, 1). Therefore, all DIs are required to achieve the best possible description of temperature and precipitation anomalies over Europe.

The above results stress the added value of integrating the four DIs. This largely results from their completion of the wind rose, which provides a finer picture of the atmospheric circulation than that derived from single zonal indices, such as the WI or the NAO. Still, some of these indices, such as the NAO may still provide complementary information to the DIs in some regions and/or seasons. To further explore 
this, we repeated the SRM of temperature and precipitation against the DIs for the 1901-2014 period (Fig. 4) but including the NAO as a predictor. Hence, the NAO will be included in the model as a skillful predictor in areas and seasons for which it improves the results obtained by the DIs. For the DIs + NAO model, we can expect NAO-related improvements in two different ways: by explaining variance in some regions where DIs are not skillful predictors or/and by increasing the explained variance already provided by the DIs. We used the summer NAO index defined by Folland et al. (2009) for the high-summer months (July-August) and the monthly NAO index of Jones et al. (1997) for the rest of the year, since the former is fundamentally different from the canonical NAO pattern. We stress that the DIs-NAO comparison carried out here aims to better quantify the amount of information provided by the DIs (using that of the NAO as a reference) rather than to state the superiority of any index. Figure 5 shows the variance in temperature and precipitation explained by the SRM with the DIs only (first and third columns) and with the DIs and the NAO (DIs + NAO, second and fourth columns). The DIs are able to account for up to $70 \%$ of the variance of the dependent (a) DJF Temp (DIs)

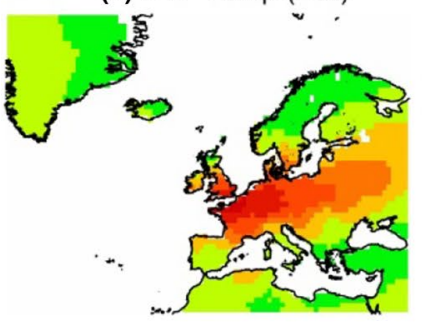

(b) MAM Temp (DIs)

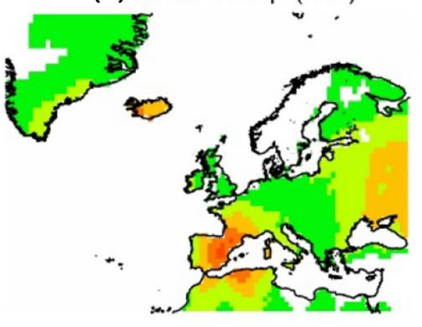

(c) JJA Temp (DIs)

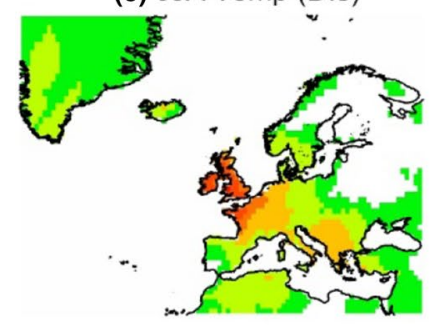

(d) SON Temp (DIs) (e) DJF Temp (DIs+NAO)

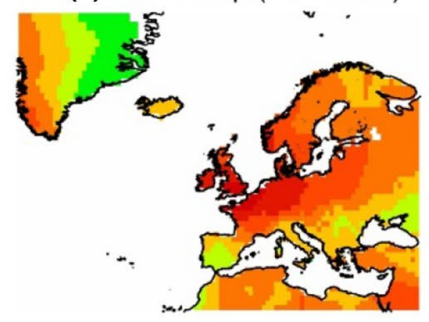

(f) MAM Temp (DIs+NAO)

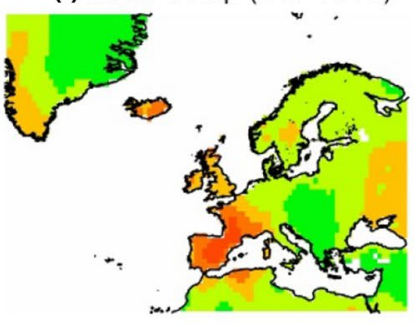

(g) JJA Temp (DIs+NAO)

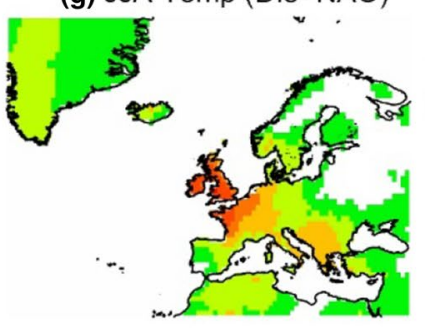

(h) SON Temp (DIs+NAO)

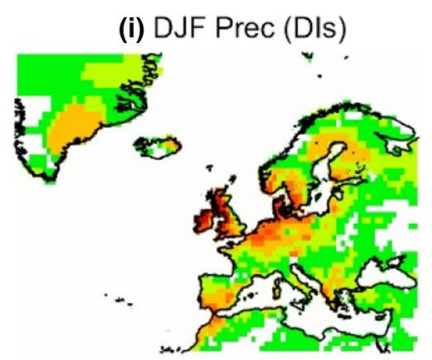

(j) MAM Prec (DIs)

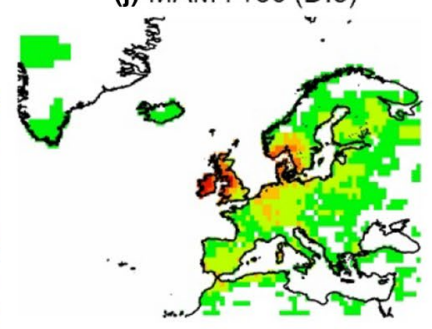

(k) JJA Prec (DIs)

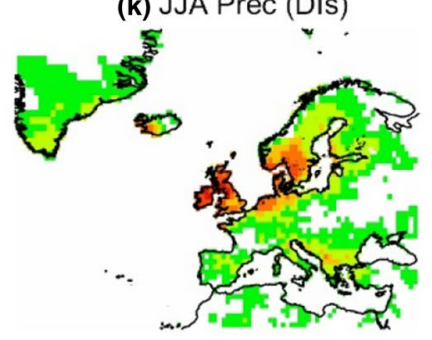

(I) SON Prec (DIs) (m) DJF Prec (DIs+NAO)

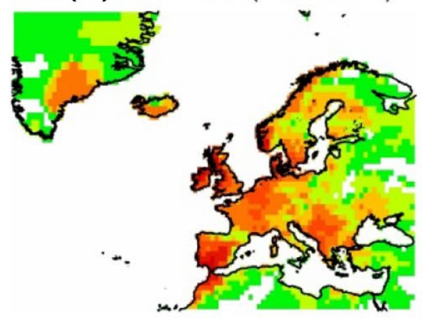

(n) MAM Prec (DIs+NAO)

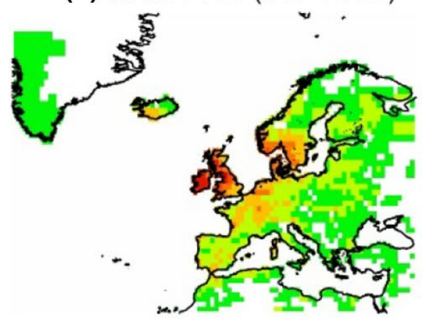

(o) JJA Prec (DIs+NAO)

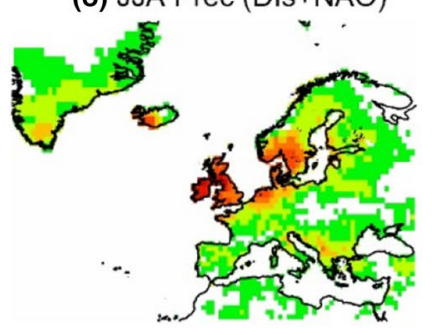

(p) SON Prec (DIs+NAO)

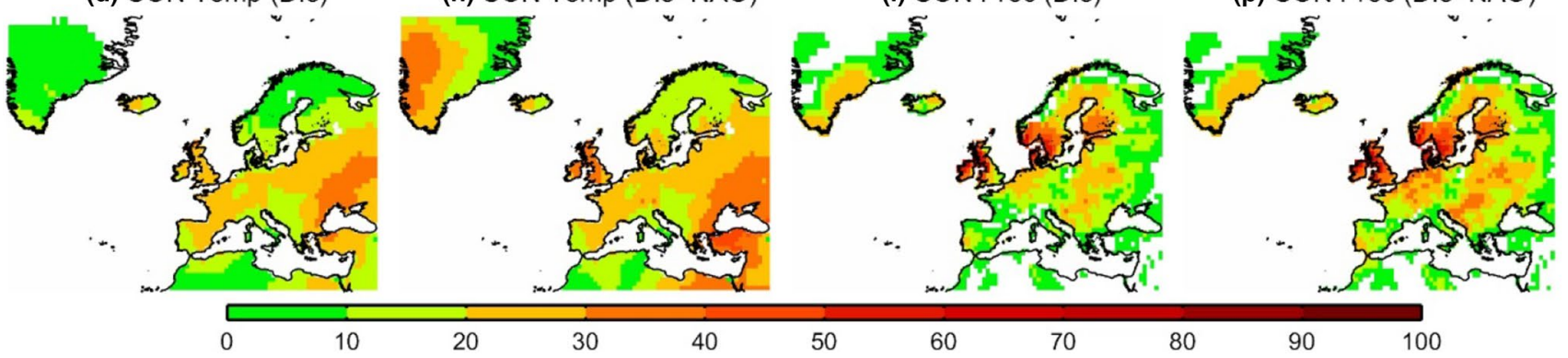

Fig. 5 Explained variance (in percentage) of seasonal: $\mathbf{a}-\mathbf{h}$ temperature and; $\mathbf{i}-\mathbf{p}$ precipitation anomalies based on Stepwise Regression Models for 1901-2014 using the DIs only (panels a-d for temperature and $\mathbf{i}-\mathbf{l}$ for precipitation) and the DIs + NAO (e-h for temperature and $\mathbf{m}-\mathbf{p}$ for precipitation) as predictors. White areas denote regions where none of the predictors is able to explain a significant amount of variance 
variable in certain regions and seasons of Europe. The inclusion of the NAO in the model adds some new areas of explained variance around the Nordic countries and Iceland for spring and summer temperature (compare Fig. 5b, c with Fig. 5f, g), and in northern and eastern Europe for winter and summer precipitation (cf. Fig. 5i, k, m, o). These areas are relatively small when compared to those where the DIs are only selected as the most skillful predictors (the rest of Europe throughout the year). On the other hand, winter is the season when the NAO brings the largest improvements. In the case of temperature, the DIs + NAO model improves the results in the Mediterranean, particularly over the eastern basin during winter and autumn (cf. Fig. 5a, d, e, h), but it does not exhibit substantial improvements in spring and summer. In general, the increase of explained variance in precipitation is not as clear as in temperature, with the only exception of winter over central Europe (cf. Fig. 5i, $\mathrm{m})$. Overall, the results indicate that the DIs are valuable indicators of the European climate, exceeding in most cases the variance accounted for by the NAO. Given the limited record of sea level pressure observations over the Atlantic, the DIs constitute an excellent alternative of the NAO to explore the atmospheric circulation over the eastern North Atlantic and European climate variability.

\section{Uncovering the past climate through the DIs}

DIs provide a detailed picture of the Euro-Atlantic atmospheric circulation and are useful predictors of the European surface climate variability. Therefore, in this section we show how the DIs help to better understand the European past climate during the period 1685-2014, from multidecadal to seasonal time scales. Figure 6 shows the standardized annual mean DIs for 1685-2014, computed from their monthly values. This period extends back to the later part of the LIA (Luterbacher et al. 2001), thereby including the transition to the present climate characterized by increasing anthropogenic forcing from human activities. There are only two periods of frequent missing data (light blue bars in Fig. 6) around 1875 and in the WWII (Fig. 1b), although some monthly and seasonal values exist for them. On interannual time scales the zonal
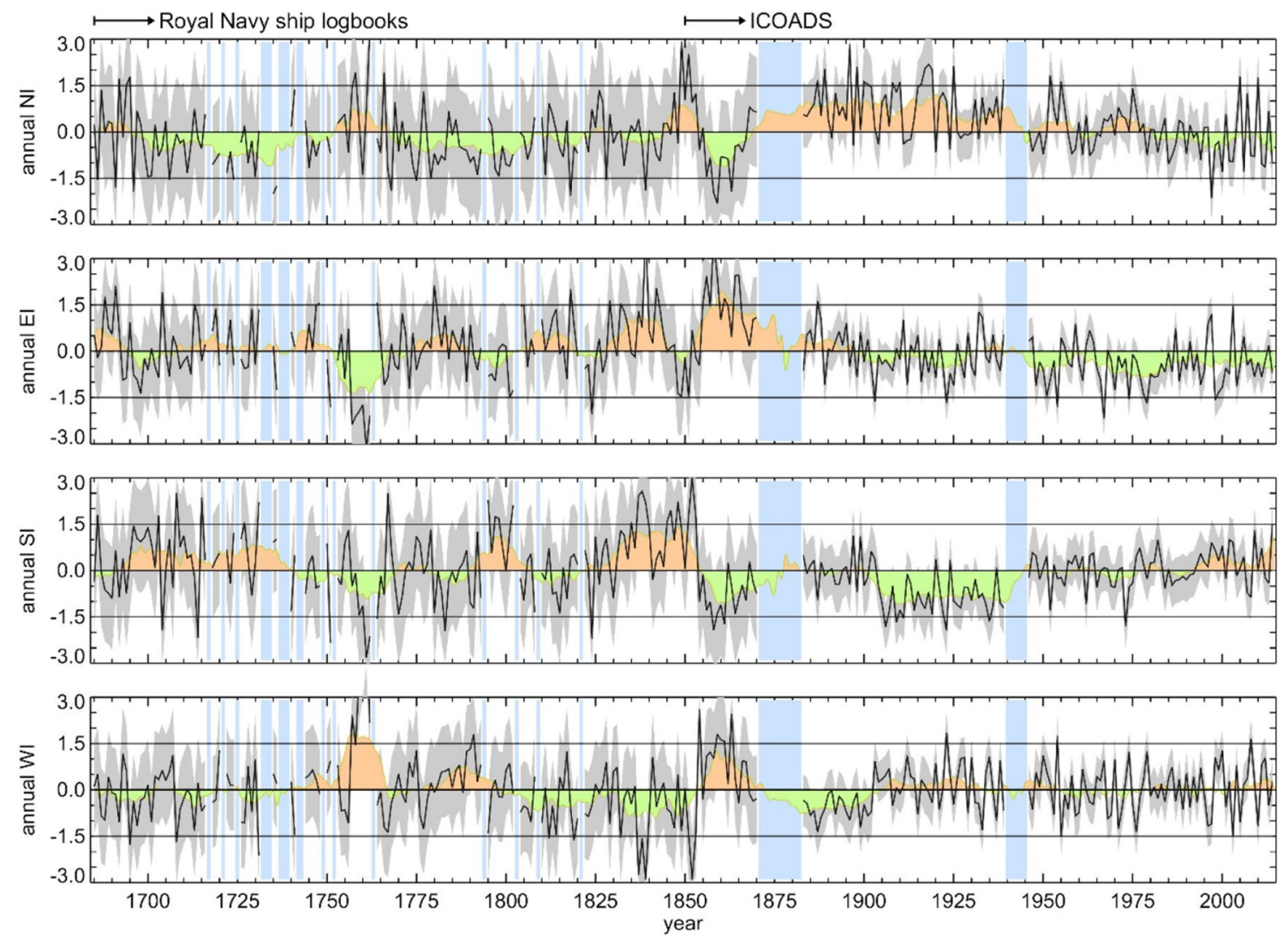

Fig. 6 Standardized annual series of DIs for 1685-2014 (black line) with the associated uncertainty (grey shading, \pm 1 sigma) and an 11-year running mean (grey line) superimposed. Green/orange shad- ing highlights periods above/below the 1685-2014 mean. Horizontal lines indicate \pm 1.5 sigma relative to the $1685-2014$ period. Vertical blue bars indicate years with at least one missing month 
DIs are significantly anti-correlated $(\mathrm{p}<0.01)$ for all calendar months of the year, and the same occurs for the meridional DIs. In addition, the annual series of SI and WI show a correlation coefficient of $-0.44(p<0.05)$ due to the predominance of south-westerly winds over the English Channel, which implies that periods with an anomalous frequency of westerlies are partially compensated by opposite changes in the southerlies. These linkages are not so evident, and actually weaken, on longer time scales (orange and green shading in Fig. 6), as explained below.

Due to the high resolution of the DIs, in this section special attention will be placed on seasonal extremes of the atmospheric circulation, herein defined as DI values above the 95th percentile and below the 5th percentile, respectively. To complement Fig. 6, Fig. 7 presents the decadal frequency (using 11-year windows centered at each year) of positive minus negative extreme occurrences of each seasonal DI, with reddish (bluish) colors indicating higher frequency of extremely positive (negative) DIs. It is worth mentioning that despite the aforementioned interannual correlations between some DIs, these relationships do not necessarily apply to seasonal extremes.

To interpret in a simple way the temperature and precipitation responses to the DI values recorded during a given period, a Circulation Index $\left(C I_{T} ; C I_{P}\right)$ has been constructed, which combines the information provided by the DIs according to their temperature (Fig. 2) and precipitation (Fig. 3) signals over Europe, respectively (Mellado-Cano et al. 2018). The index $C I_{T}=(S I+W I)-(N I+E I)$ summarizes the overall temperature signals of the DIs during the cold half of the year, when enhanced southerlies and westerlies (easterlies and northerlies) are associated with warmer (colder) conditions over large parts of Europe (Figs. 2a-d, S6e-h). Recall that the DIs fingerprints in temperature vary seasonally (Fig. 2), and hence this index is reformulated as $C I_{T}=(S I+E I)-(N I+W I)$ in the warm half of the year to account for the reversed temperature signal of the zonal DIs. Therefore, positive (negative) values of $\mathrm{CI}_{T}$ indicate dynamically-prone warm (cold) conditions on continental scale regardless of the season. Unlike temperature, the precipitation signal shows a consistent response all year-round
Fig. 7 Frequency difference of positive minus negative seasonal DIs extremes for running 11-year intervals of the 16852014 period (x-axis), with red (blue) shading denoting positive (negative) differences. Positive (negative) DIs extremes are defined as those above the 95th (below the 5th) percentile of their seasonal 1685-2014 distribution. Seasons are displayed from the top (winter, DJF) to the bottom (autumn, SON) in the left y-axis. For each season, the DIs are arranged clockwise from the NI (top of each season) to the WI (bottom of each season), as shown for the winter season in the right $y$-axis

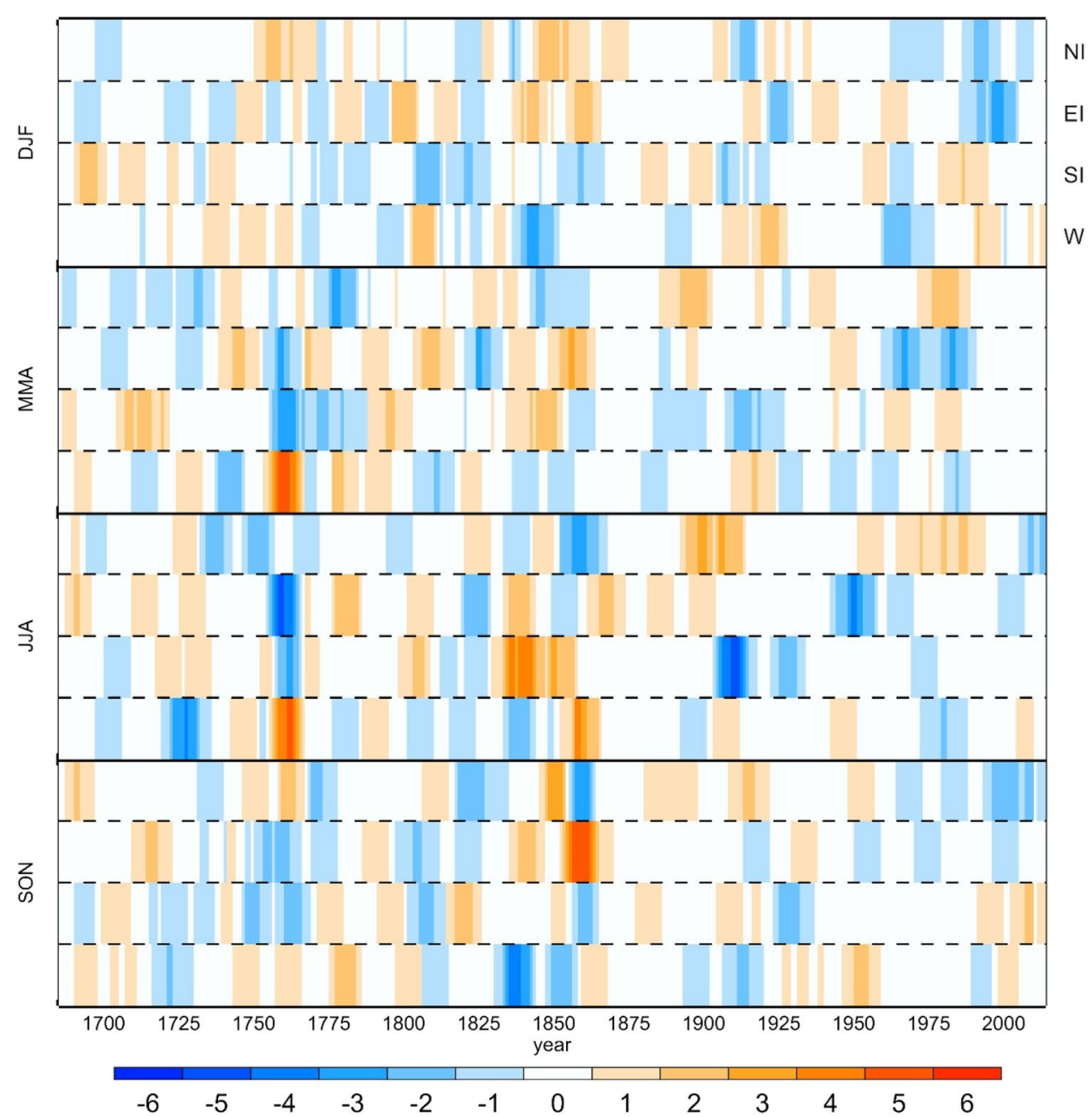


(Fig. 3), with zonal DIs explaining a substantial fraction of its variability over central and northern Europe (Fig. 4i-1). As such, $C I_{P}=(W I-E I)$ is an indicator of the precipitation anomalies that can be expected therein from the atmospheric circulation. Using all this information we have assessed the most relevant features of the atmospheric circulation for the last three centuries on different time scales (from multidecadal periods to seasonal extremes), and the associated surface conditions over large parts of Europe.

\subsection{General overview}

On multi-decadal time scales, the DIs series are dominated by large variability (Fig. 6). We have first focused on longterm changes by looking for differences between the preindustrial (1685-1869) and industrial (1870-2014) halves of the seasonal DI series. Some differences are significant (95\% confidence level). More specifically, the industrial era is characterized by a decline of the annual easterlies $(-2.6 \%)$, spring and summer southerlies $(-2.8 \%$ and $-8.5 \%$, respectively) and autumn westerlies $(-2.4 \%)$, as well as an increase of the northerlies in spring and summer (4.5\% and $6.5 \%$ ) when compared with the preindustrial period. These differences should not necessarily be interpreted as a response to anthropogenic factors. In fact, the mean values of the last decades are not exceptional in the context of the last 330 years. Decreases in DIs variability after the mid19th century are also apparent in Fig. 6, although they are not significant $(\mathrm{p}<0.1)$ for all seasons of a given DI or for all DIs in the same season, according to an F-test of equality of variances. Changes in variance are larger for the spring and summer DIs, but the detection of significant differences often depends on the year chosen to define the pre- and postmid-19th century periods.

On multi-decadal (50 years) time scales, two periods (1701-1750 and 1826-1875) stand out in the annual time series of the DIs (Fig. 6). The most remarkable circulation signatures of the former $\left(\overline{C I}_{P}(1701-1750)=-0.32\right)$ support the dry conditions reported in Europe during the first half of 18 th century (Pauling et al. 2006). The second period displayed similar features $\left(\overline{C I}_{P}(1826-1875)=-0.84\right)$ but is almost unnoticed in the literature, with the exception of Casty et al. (2005), who suggested 1830 as a year of transition from wet to dry conditions over Europe. Moreover, some shorter intervals within these periods presented $C I_{P}$ values below $-1 \mathrm{SD}$, indicating the presence of dry extremes (Fig. 7). In spite of the overall dryness of continental Europe due to the prevalence of EI, the results shown that in both periods the SI stands out over the NI and WI $\overline{S I}(1701-1750)=0.42 ; \overline{S I}(1826-1875)=0.31)$, accordingly the DIs also indicate that relatively wetter conditions should have occurred over the UK and the Iberian Peninsula in both of them (Fig. 3b, c, f, g). Supporting this result, previous studies have reported above average rainfall in Lisbon between 1864 and 1875, as well as unusually wet years in the Iberian Peninsula, such as 1856 (Kutiel and Trigo 2014; Domínguez-Castro et al. 2015).

On the other hand, the 20-year periods of 1760-1780, 1840-1860 and 1905-1925 are exceptional, standing out by their high frequency of extreme DIs (Fig. 7). During summer and spring, the 1760-1780 period exhibited recurrently positive (negative) extreme WI (SI) values, associated to cold conditions over northern (central) Europe, according to Fig. 2h (Fig. 2g). Differently, winters (autumns) showed an alternation of negative and positive extremes of zonal (meridional) DIs, which agrees with Cornes et al. (2013), who reported a wide range of circulation extremes during the winters of 1760s. On the other hand, the years around the mid-19th century were prone to widespread cooling during the cold seasons, as featured by positive (negative) values of NI and EI (SI and WI) in Fig. 6. This result agrees with the high frequency of easterly LWT in Delaygue et al. (2019) and with Küttel et al. (2010), who used station pressure series and marine information to conclude that the cold decade of the 1840s was followed by an even colder period. Finally, the beginning of the 20th century (1905-1945) exhibited recurrent negative extremes of SI in all seasons (Fig. 7), indicating persistent high-pressure systems over the Atlantic throughout the year (Fig. 2c, g). They were accompanied by positive extremes of WI during winter, enhancing the warm conditions in central and eastern Europe (Fig. 2d). Both results agree with the strong zonal circulation reported by Slonosky et al. (2001) and Delaygue et al. (2019) during 1900-1930 and the warm European conditions described by Küttel et al. (2010) in the 1910s and 1920s.

The recurrent frequency of multi-decadal anomalies of the DIs involves a substantial variability of the atmospheric circulation on these time scales. An interesting example is found during the LMM (1685-1715). This period was characterized by decreased westerlies (Barriopedro et al. 2014). However, the other DIs reveal that the winter decrease was compensated by an increase of northerlies and easterlies (southerlies) during the first (second) half of the LMM (not shown), pointing to the presence of substantial inter-decadal variability (Mellado-Cano et al. 2018).

\subsection{European past climate beyond the 19th century}

In what follows, we will mainly focus on the less well-documented period spanning from 1685 to 1899 . On decadal time scales the DIs provide new insights into periods such as the 1760s and $1800 \mathrm{~s}$, for which the atmospheric circulation is still far from clear, with discrepancies between reconstructed NAO indices (Luterbacher et al. 2002; Cook et al. 2002; Cornes et al. 2013). The winter DIs display a wide range of extreme values in the four directions (Fig. 7), 
including the largest positive value of the WI time series in $1761\left(W I_{D J F}(1761)=5.54\right)$. The large variability in all DIs reflects that the meridional circulation also played an important role during both periods, which may explain the discrepancies between the NAO indices. This calls for caution when characterizing atmospheric circulation in terms of the NAO alone, which mainly provides a measure of the zonal flow and disregards other important patterns of atmospheric circulation, such as the EA (see Mellado-Cano et al. 2019).

There are other outstanding decadal periods in the DIs, which mainly occur during winter. The winters of 1717-1726 and 1730-1739 stand out by the prevalence of SI and WI over EI and NI, and hence the largest $C I_{T}$ values on record $\left(\overline{C I}_{T_{-} D J F}(1717-1726)=2.10 ; \overline{C I}_{T_{-} D J F}\right.$ $(1730-1739)=2.16)$, thus indicating extraordinary warm conditions. In fact, the multi-proxy reconstruction of Luterbacher et al. (2004) points to the close decade of 1733-1742 as the warmest one of 1500-2000, only surpassed by the end of the 20th century (1989-1998). On the contrary, 1687-1696 and 1810-1819 are herein ascribed to cold winter conditions according to their $C I_{T}$ values $\left(\overline{C I}_{T_{-} D J F}\right.$ $\left.(1687-1696)=-1.29 ; \overline{C I}_{T_{-} D J F}(1810-1819)=-1.24\right)$. The first period took place during the LMM and the socalled 'climax of the LIA' (Luterbacher et al. 2001), and includes some of the most exceptional cold episodes in the $C I_{T}$ series, such as the $1692\left(C I_{T_{-} D J F}(1692)=-4.31\right)$ and $1695\left(C I_{T_{-} D J F}(1695)=-4.64\right)$ winters, both reported by previous studies (Luterbacher et al. 2001; Slonosky et al. 2001; Casty et al. 2005; Mellado-Cano et al. 2018). On the other hand, the winters of 1810-1819 displayed large positive anomalies in the EI $\left(\overline{E I}_{D J F}(1810-1819)=0.67\right)$ and positive extremes of NI (Fig. 7), both indicating coldness and dryness. This is in good agreement with previous studies (e.g. Briffa 2000; D'Arrigo et al. 2006), which described the 1813-1822 decade as one of the coldest in the Northern Hemisphere.

The resolution of the DIs allows us to examine the atmospheric circulation during extreme episodes on seasonal (actually monthly) time scales and in seasons other than winter. For example, the 1807 summer displayed outstanding values of the meridional indices $\left(N I_{J J A}(1807)=-1.4 ; S I_{J J A}(1807)=1.93\right)$, thus indicating warm conditions over central Europe (Fig. 2e, g; see also Casty et al. 2005). A more recent example can be given for the 1902 summer, the coldest of the last 500 years in the European temperature reconstruction of Luterbacher et al. (2004). This summer was characterized by an extremely positive value of the NI $\left(N I_{J J A}(1902)=2.19\right)$, favoring colder temperatures over the Mediterranean basin and Greenland (Fig. 2e). While other summers of the early 20th century were also characterized by extreme values of the NI (Fig. 7), the widespread character of this summer was likely due to additional cooling induced by the decreased easterlies $\left(E I_{J J A}(1902)=-0.8\right)$ over northwestern Europe (Fig. 2f).

\section{Impact of tropical volcanic eruptions}

The DIs extend the currently available observational record of atmospheric circulation indices by at least 150 years, thus allowing a better characterization of the internal variability and the fingerprints of external forcings in atmospheric circulation. Herein, we exploit this advantage to examine the DIs response to major tropical volcanic eruptions. While their effects on European climate during summer and winter have been reported before (e.g. Fischer et al. 2007; Timmreck 2012; Wegmann et al. 2014; Lutebacher et al. 2016; Rao et al. 2017), they have been largely inferred from multi-proxy reconstructions of near-surface fields for the last 500 years, even when some of the volcanic signatures are assumed to occur through changes in the atmospheric circulation (Robock 2000), at least for some of the largest eruptions such as Tambora in 1815 (e.g. Trigo et al. 2009). Moreover, the regional responses in seasons other than winter and summer are less documented. To the best of our knowledge, this assessment provides the first observational evidence of the year-round Euro-Atlantic circulation response to tropical volcanic eruptions of the last three centuries.

Volcanic eruptions have been obtained from an updated version of the VolcanEESM database (Neely III and Schmidt 2016). This updated version extends the previous record to $850 \mathrm{AD}$, based on a cross-comparison of multiple evidences from sulfate deposition in ice cores (Sigl et al. 2015; Toohey and Sigl 2017) and the Global Volcanism Program (https:// volcano.si.edu/; Ryan Neely III, personal communication). Following previous studies (e.g. Fischer et al. 2007; Crowley and Unterman 2013), we selected the largest tropical eruptions from 1685, defined as those with a Volcanic Explosivity Index (VEI) equal or larger than 5 . This criterion yields nine events, all of them after 1800 (Table S2). Superposed Epoch Analyses (SEA) are often employed to explore the seasonal responses, which are expressed as differences with respect to the averaged conditions for the 5 years before the time of the eruption (year 0). However, different criteria are adopted to determine the seasons of the years 0 and +1 (Robock 2000; Fischer et al. 2007; Lutebacher et al. 2016). Seasons of year $0(+1)$ are herein defined as the first (second) ones occurring after the volcanic eruption (Sigl et al. 2015; Lutebacher et al. 2016). As the largest impact may arguably occur in any of them, depending on the timing of the eruption and the large-scale circulation at that time, we take for each DI the largest absolute standardized seasonal anomaly of years 0 and +1 . This criterion may overestimate the volcanic response, as long as there is consistency among the volcanic eruptions in the sign of DIs anomalies. 
Therefore, this SEA approach (Fig. 8) would provide an upper estimate of the Euro-Atlantic circulation responses to major tropical eruptions. In addition, we have performed the SEA taking the average of the DIs signals for years 0 and + 1 , which provides a more conservative estimate. The results of this second approach (see Figure S8) are qualitatively similar to those obtained in Fig. 8, albeit the significance is lost in most DIs and seasons. Further analyses indicate that this is partially due to different (sometimes opposite) DIs anomalies for the years 0 and +1 of several volcanic eruptions, indicating that the dynamical signatures do not necessarily persist from 1 year to the next. In these cases, it is difficult to infer whether our first SEA approach is wrongly interpreting the selected year as a forced response or if the second approach is masking the volcanic signal. Therefore, in the remaining of this section, we only describe those aspects that are qualitatively consistent (i.e. signals of the same sign) in both approaches.

The results indicate that some of the largest anomalies are observed for the SI and EI indices (Figs. 8, S8). The cold half of the year is characterized by a southward veering of the wind, while zonal indices (mainly EI) seem to play a major role in the warm seasons, which are characterized by spring increases and summer decreases in EI (only significant in spring, though). Surprisingly, there are no significant changes in the WI in any season or SEA approach. This is in disagreement with previous studies, which attributed the post-eruption European winter warming to positive NAOlike phases (e.g. Fischer et al. 2007). Regarding summer, the decrease of the EI provides additional evidences of dynamical responses to tropical eruptions during this season, which are characterized by a southward shift of the storm tracks (Fig. 3f), likely reinforced by an increase of SI (although the latter is very small in the mean SEA approach). This signature of the summer jet has also been linked with a weakened African monsoon in previous studies (e.g. Wegmann et al. 2014; Raible et al. 2016; Paik and Min 2018). Our results also suggest some contribution of the atmospheric circulation to the summer European cooling reported after major tropical eruptions (e.g. Fischer et al. 2007; Sigl et al. 2015). However, the large spread associated with the composited values of the DIs points to large case-to-case variability, suggesting that the overall signal could be dominated by a few volcanic eruptions, for which the atmospheric circulation might well reflect internal variability. As an example, the Tambora's eruption (April 1815) that preceded the year without summer (Trigo et al. 2009; Luterbacher and Pfister 2015) was characterized by the prevalence of westerlies during the two post-eruption summers and winters, which does not fully agree with the composite picture described above.

To better frame these results, we reconstructed the nearsurface signatures associated with the post-eruption DIs by using the SRM of Sect. 4, which integrates the joint effects of all DIs and interpret them in terms of temperature and precipitation. Although the DIs signals derived from the two SEA approaches tend to agree, their combined effects in the near-surface variables of transitional seasons (MAM and SON) do not (they often change from year 0 to +1 ). Therefore, the analysis will be restricted to winter and summer, which are not affected by this issue. Figure 9 shows the seasonal composites of temperature and precipitation anomalies, as inferred from the DIs signals after the nine tropical volcanic eruptions and the first SEA approach. The results confirm that post-eruption winters are prone to warm conditions over central and northeastern Europe (Fig. 9a), while summers tend to show cooling in central and southern Europe (Fig. 9b). This is in overall agreement with previous studies (Robock 2000; Fischer et al. 2007; Lutebacher et al. 2016). Similar to Fischer et al. (2007), there is also a dry-wet anomaly dipole over southeastern-northern Europe in winter (Fig. 9c), and over parts of northern-southern Europe in summer (Fig. 9d). While our results are relatively robust among the considered events (see hatching in Fig. 9) and qualitatively agree with previous studies, they also indicate that the surface responses induced by the atmospheric circulation cannot be simply interpreted in terms of changes in zonality, as previously suggested.

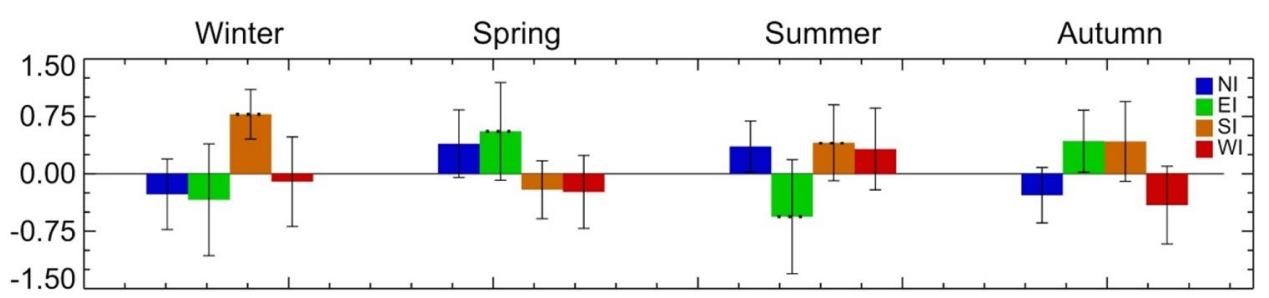

Fig. 8 Superposed epoch analyses of the seasonal standardized DIs following the strongest $(\mathrm{VEI} \geq 5$ ) tropical volcanic eruptions of 1685-2014. For each DI (colored bars, see legend) and season, anomalies are expressed as the difference between the largest standardized anomaly of the years 0 and +1 and the averaged value for the 5 years preceding each volcanic eruption. Dotted tops indicate significance at the $90 \%$ confidence level after a bootstrap of 5000 trials, each one containing the same number and calendar months of volcanic eruptions, but with random years of occurrence. Error bars indicate the \pm 0.5 sigma level 
(a) DJF Temp

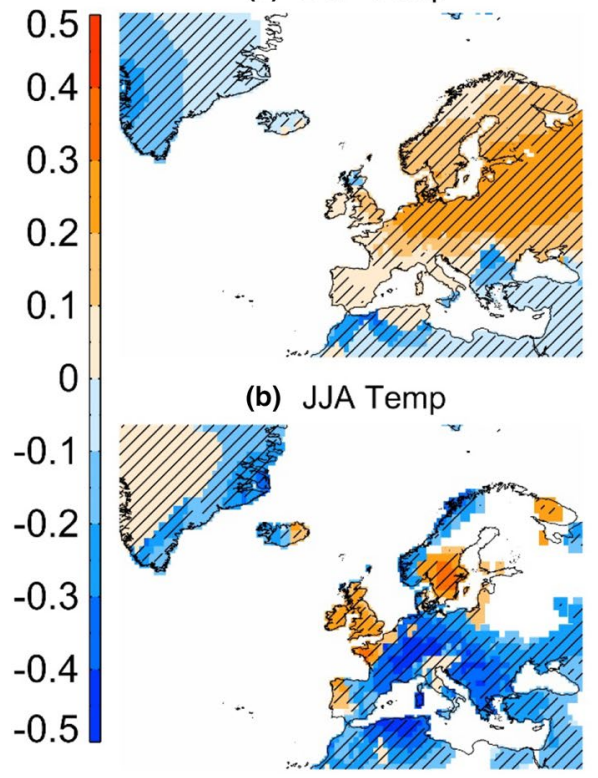

Fig. 9 Reconstructed mean seasonal anomalies (with respect to 1901-2014) of: a, b temperature $\left({ }^{\circ} \mathrm{C}\right.$ ) and; c, $\mathbf{d}$ precipitation (in percentage of normal) following explosive tropical volcanic eruptions of 1685-2014. Red/blue colors indicate positive/negative temperature anomalies and below-/above-normal precipitation. The reconstructed anomalies are derived by applying the Stepwise Regression Model of

\section{Conclusions}

This study presents four observational indices of the atmospheric circulation over the eastern North Atlantic based on daily wind direction observations from the English Channel for 1685-2014. The main conclusions can be summarized as follows:

- Ships observations from ICOADS (1850-2014) were extended back to 1685 by using more than 70,000 wind direction records abstracted from ships' logbooks. A robust methodology was designed to obtain the monthly frequency of wind direction in the four cardinal directions (i.e. the Northerly, Easterly, Southerly and Westerly Indices, NI, EI, SI and WI), as well as the uncertainties associated with sampling issues and changes in the number of observations. These Directional Indices (DIs) are the longest and highest resolution observational indices of atmospheric circulation over the North Atlantic currently available, providing an excellent framework to study the European climate from monthly to centennial time scales.

- The DIs are subject to substantial variability from interannual to multidecadal and longer time scales, including some differences between industrial (1870-2014) and pre-industrial (1685-1869) periods, such as declines in (c) DJF Prec

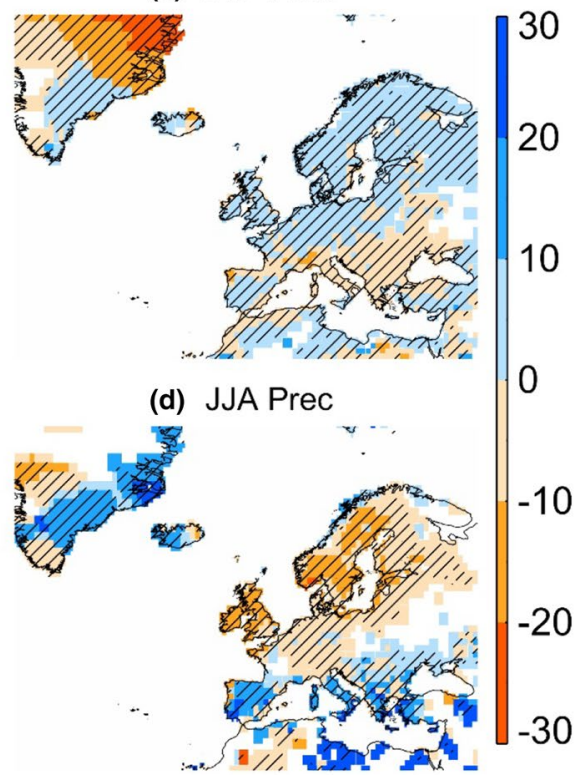

the DIs series for 1901-2014 to the DIs anomalies recorded after each volcanic eruption. White areas show regions where none of the DIs is able to explain a significant amount of variance. Hatching indicates regions for which $66 \%$ of the volcanic eruptions display an anomaly of the same sign. See text for details

the easterlies, more pronounced during winter, and in the westerlies during autumn. These changes may reflect a dynamical response to external forcings, a previously unnoticed multicentennial variability or other issues not addressed herein. This would be informative for future projections but with very different implications: while the first interpretation could provide guidance on potential dynamical responses to increasing greenhouse gas concentrations, the second one would mean that we may be underestimating the range of internal variability, at least on very low frequencies. Future modeling studies are required to further evaluate these hypotheses.

- By covering all principal wind directions, the DIs give a more complete picture of the atmospheric circulation than that provided by zonal indices such as the North Atlantic Oscillation (NAO). In fact, they shed light on some inconsistencies between NAO indices for specific periods, which can be explained by the presence of a marked meridional circulation. In this sense, the DIs arise as an alternative to explore the NAO during the last three centuries, the complexities of the Euro-Atlantic atmospheric circulation and their climatic implications.

- The DIs reflect synoptic-to-large-scale changes in the atmospheric circulation, often involving the eddy-driven jet stream, and thus modulating the thermal advection and moisture fluxes into the continent. As such, fluc- 
tuations in the DIs are associated with precipitation and temperature anomalies over large areas of Europe in all seasons. The climatic signals of the DIs are spatially complementary, with zonal and meridional indices frequently affecting different areas. Precipitation is strongly controlled by moisture advection, mainly associated with the zonal DIs and shows a robust and coherent response throughout the year. Differently, the spatial response in temperature is largely explained by temperature advection and radiative processes. As a consequence, the temperature signal associated with the zonal DIs reverses during the warm half of the year. The combined information of the four DIs captures all year-round climatic signals in terms of temperature and precipitation, making them excellent benchmarks for proxy calibrations.

- The surface signals of the DIs allow us to infer anomalous conditions driven by atmospheric circulation, thus providing new insights into the European climate since 1685. For example, the 1717-1727 and 1687-1697 winters, as well as the 1835-1839 and 1757-1762 summers, stand out as one of the warmest and coldest periods before the 20th century. On longer time scales, the first half of 18 th century and 1825-1875 were relatively dry during all months. While the identification of these periods is based on dynamical arguments only, the soinferred anomalies could be compared with the actual conditions previously reported in the historical record in order to quantify the role of non-dynamical processes, opening new opportunities to explore past climate and its variability.

- We provide the first observational evidence of the yearround Euro-Atlantic circulation signatures following the strongest tropical volcanic eruptions since 1685 . Overall, the results confirm the well-reported winter warming over Europe, but also show that the associated atmospheric circulation signals are more complex than previously thought, involving changes in the meridional flow and substantial case-to-case and year-to-year variability. According to our findings the atmospheric circulation would have played a role in the post-eruption European summer cooling. We also provide new insights into the less documented transitional seasons. This supports the idea that explosive tropical eruptions can induce measurable changes in the atmospheric circulation throughout the year. Similar analyses could be applied to explore the circulation responses to other natural forcings such as the 11-year solar cycle (e.g. Barriopedro et al. 2011).

In summary, we have demonstrated the value of ship's logbooks as an observational source to characterize the Euro-Atlantic atmospheric circulation from monthly to multi-decadal time scales, and the associated near-surface climate variability over Europe. This represents a substantial step forward, since most of the current knowledge of the European climate for the last centuries is based on multiproxy reconstructions, which are often biased towards the summer season.

Acknowledgements This work is a contribution to UID/ GEO/50019/2013-Instituto Dom Luiz. Javier Mellado-Cano was supported by the Portuguese Science Foundation (FCT) through the $\mathrm{PhD}$ fellowship PD/BD/106028/2014, and by the Spanish Ministry of Economy and Competitiveness through the PALEOSTRAT (CGL201569699-R) project through the contract PAII18/19/2/2019/14. Ricardo M. Trigo was funded through the Portuguese Science Foundation (FCT) HOLMODRIVE (PTDC/CTA-GEO/29029/2018) project. The authors are particularly thankful to the NOAA for providing the ICOADS 3.0 dataset (http://icoads.noaa.gov/). Temperature data and precipitation were provided by the CRU (http://www.cru.uea.ac.uk) and the GPCC (http://gpcc.dwd.de), respectively. Support for the Twentieth Century Reanalysis Project version $2 \mathrm{c}$ dataset is provided by the U.S. Department of Energy, Office of Science Biological and Environmental Research (BER), and by the National Oceanic and Atmospheric Administration Climate Program Office. The authors are grateful to D. Wheeler and M.C Álvarez-Castro for their help on the abstraction of wind direction data from the Royal Navy ships' logbooks. The authors are grateful to Ryan Neely III for providing an updated version of the VolcanEESM database since 1685. We thank two anonymous reviewers for their useful comments that helped to improve the original manuscript.

Data availability The seasonal DIs time series are available at https ://doi.pangaea.de/10.1594/PANGAEA.906067 (Mellado-Cano et al. 2019).

Open Access This article is distributed under the terms of the Creative Commons Attribution 4.0 International License (http://creativeco mmons.org/licenses/by/4.0/), which permits unrestricted use, distribution, and reproduction in any medium, provided you give appropriate credit to the original author(s) and the source, provide a link to the Creative Commons license, and indicate if changes were made.

\section{References}

Alexandersson H (1986) A homogeneity test applied to precipitation data. J Climatol 6:661-675

Alexandersson H, Moberg A (1997) Homogenization of Swedish temperature data. Part I: homogeneity test for linear trends. Int J Climatol 17:25-34

Ayre M, Nicholls J, Ward C, Wheeler D (2015) Ships' logbooks from the Arctic in the pre-instrumental period. Geosci Data J 2(2):5362. https://doi.org/10.1002/gdj3.27

Barnston AG, Livezey RE (1987) Classification, seasonality and persistence of low-frequency atmospheric circulation patterns. Mon Weather Rev 115:1083-1126. https://doi.org/10.1175/15200493(1987)115\%3c1083:CSAPOL\%3e2.0.CO;2

Barriopedro D, Fischer EM, Luterbacher J, Trigo R, Garcia-Herrera R (2011) The hot summer of 2010: redrawing the temperature record map of Europe. Science 332:220-224

Barriopedro D, Gallego D, Alvarez-Castro MC, García-Herrera R, Wheeler D, Peña-Ortiz C, Barbosa SM (2014) Witnessing North Atlantic Westerlies variability from ship's logbooks (16852008). Clim Dyn 43:939-955. https://doi.org/10.1007/s0038 2-013-1957-8 
Bladé I, Liebmann B, Fortuny D, van Oldenborgh G (2012) Observed and simulated impacts of the summer NAO in Europe: implications for projected drying in the Mediterranean region. Clim Dyn 39:709-727. https://doi.org/10.1007/s00382-011-1195-x

Briffa KR (2000) Annual climate variability in the Holocene: interpreting the message of ancient trees. Quatern Sci Rev 19:87e105

Brown TJ, Hall BL (1999) The use of t values in climatological composite analyses. J Clim 12:2941-2944

Casty C, Wanner H, Luterbacher J, Esper J, Böhm R (2005) Temperature and precipitation variability in the European Alps since 1500. Int J Climatol 25:1855-1880

Compo GP, Whitaker JS, Sardeshmukh PD, Matsui N, Allan RJ, Yin $\mathrm{X}$, Gleason BE Jr, Vose RS, Rutledge G, Bessemoulin P, Broennimann S, Brunet M, Crouthamel RI, Grant AN, Groisman PY, Jones PD, Kruk MC, Kruger AC, Marshall GJ, Maugeri M, Mok HY, Nordli O, Ross TF, Trigo RM, Wang XL, Woodruff SD, Worley SJ (2011) The twentieth century reanalysis project. Q J R Meteorol Soc 137:1-28. https://doi.org/10.1002/qj.776

Cook ER, D'Arrigo RD, Mann ME (2002) A well-verified, multiproxy reconstruction of the winter North Atlantic Oscillation Index since A.D. 1400. J Clim 15:1754-1764. https:// doi.org/10.1175/1520-0442(2002)015\%3c1754:AWVMR $\mathrm{O} \% 3 \mathrm{e} 2.0 . \mathrm{CO} ; 2$

Cornes RC, Jones PD, Briffa KR, Osborn TJ (2013) Estimates of the North Atlantic Oscillation back to 1692 using a ParisLondon westerly index. Int J Climatol 33:228-248. https://doi. org/10.1002/joc.3416

Crowley TJ, Unterman MB (2013) Technical details concerning development of a $1200 \mathrm{yr}$ proxy index for global volcanism. Earth Syst Sci Data 5(1):187-197

D'Arrigo R, Wilson R, Jacoby G (2006) On the long-term context for late twentieth century warming. J Geophys Res 111:D03103. https://doi.org/10.1029/2005JD006352

Delaygue G, Brönnimann S, Jones PD, Juliette B, Mikhaël S (2019) Reconstruction of Lamb weather type series back to the eighteenth century. Clim Dyn 52:6131. https://doi.org/10.1007/s0038 2-018-4506-7

Domínguez-Castro F, Ramos AM, García-Herrera R, Trigo RM (2015) Iberian extreme precipitation 1855/1856: an analysis from early instrumental observations and documentary sources. Int J Climatol 35:142-153. https://doi.org/10.1002/joc.3973

Fischer EM, Luterbacher J, Zorita E, Tett SFB, Casty C, Wanner H (2007) European climate response to tropical volcanic eruptions over the last half millennium. Geophys Res Lett 34:L05707. https ://doi.org/10.1029/2006GL027992

Folland C, Knight J, Linderholm H, Fereday D, Ineson S, Hurrell JW (2009) The summer North Atlantic Oscillation: past, present and future. J Clim 22:1082-1103. https://doi.org/10.1175/2008JCLI24 59.1

Freeman E, Woodruff SD, Worley SJ, Lubker SJ, Kent EC, Angel WE, Berry DI, Brohan P, Eastman R, Gates L, Gloeden W, Ji Z, Lawrimore J, Rayner NA, Rosenhagen G, Smith SR (2017) ICOADS Release 3.0: a major update to the historical marine climate record. Int J Climatol 37:2211-2232. https://doi.org/10.1002/ joc. 4775

Gallego D, Ordóñez P, Ribera P, Peña-Ortiz C, García-Herrera R (2015) An instrumental index of the West African Monsoon back to the nineteenth century. Q J R Meteorolol Soc 141:3166-3176. https://doi.org/10.1002/qj.2601

Gallego D, García-Herrera R, Peña-Ortiz C, Ribera P (2017) The steady enhancement of the Australian Summer Monsoon in the last 200 years. Nature. https://doi.org/10.1038/s41598-017-16414-1

García-Herrera R, Díaz J, Trigo RM, Luterbacher J, Fischer EM (2010) A review of the European summer heat wave of 2003. Crit Rev Environ Sci Technol 40(4):267-306. https://doi. org/10.1080/10643380802238137
García-Herrera R, Barriopedro D, Gallego D, Mellado-Cano J, Wheeler D, Wilkinson C (2018) Understanding weather and climate of the last 300 years from ships logbooks

Gimeno L, Stohl A, Trigo RM, Dominguez F, Yoshimura K, Yu L, Drumond A, Durán-Quesada AM, Nieto R (2012) Oceanic and terrestrial sources of continental precipitation. Rev Geophys 50:RG4003. https://doi.org/10.1029/2012rg000389

Gómez-Delgado, F de Paula, Gallego D, Peña-Ortiz C, Vega I, Ribera P, García-Herrera R (2018) Characterization of the long term variability of the Etesian wind from historical wind observations. Submitted to Global and Planetary Change

Hanna E, Cropper TE, Hall RJ, Cappelen J (2016) Greenland Blocking Index 1851-2015: a regional climate change signal. Int J Climatol 36:4847-4861. https://doi.org/10.1002/joc.4673

Harris I, Jones PD, Osborn TJ, Lister DH (2014) Updated high-resolution grids of monthly climatic observations-the CRU TS3.10 dataset. Int J Climatol 34:623-642. https://doi.org/10.1002/ joc. 3711

Jackson A, Jonkers ART, Walker MR (2000) Four centuries of geomagnetic secular variation from historical records. Philos Trans R Soc 358A:957-990. https://doi.org/10.1098/rsta.2000.0569

Jones PD, Jonsson T, Wheeler D (1997) Extension to the North Atlantic Oscillation using early instrumental pressure observations from Gibraltar and south-west Iceland. Int J Climatol 17:1433-1450. https://doi.org/10.1002/(SICI)1097-0088(19971 115)17:13,1433:AID-JOC203.3.0.CO;2-P

Kidston J, Scaife A, Hardiman S, Mitchell D, Butchart N, Baldwin M, Gray L (2015) Stratospheric influence on tropospheric jet streams, storm tracks and surface weather. Nat Geosci 8:433-440. https:// doi.org/10.1038/ngeo2424

Kutiel H, Trigo RM (2014) The rainfall regime in Lisbon in the last 150 years. Theoret Appl Climatol. https://doi.org/10.1007/s0070 4-013-1066-y

Küttel M, Xoplaki E, Gallego D, Luterbacher J, García-Herrera R, Allan R, Barriendos M, Jones PD, Wanner H (2010) The importance of ship log data: reconstructing North Atlantic, European and Mediterranean Sea level pressure fields back to 1750. Clim Dyn 34:1115-1128. https://doi.org/10.1007/s00382-009-0577-9

Küttel M, Luterbacher J, Wanner H (2011) Multidecadal changes in winter circulation-climate relationship in Europe: frequency variations, within-type modifications, and long-term trends. Clim Dyn 36:957-972. https://doi.org/10.1007/s00382-009-0737-y

Lutebacher J, Werner JP, Smerdon JE, Fernández-Donado L, GonzálezRouco FJ, Barriopedro D, Ljungqvist C, Büntgen U, Zorita E, Wagner S, Esper J, McCarroll D, Toreti A, Frank D, Jungclaus $\mathrm{JH}$, Barriendos M, Bertolin C, Bothe O, Brázdil R, Camuffo D, Dobrovolny P, Gagen M, García-Bustamante E, Ge Q, JómezNavarro JJ, Guiot J, Hao Z, Hegerl GC, Holmgren K, Klimenko VV, Marín-Chivelet J, Pfister C, Roberts N, Schindler A, Schurer A, Scolomina O, von Gunten L, Wahl E, Wanner H, Wetter O, Xoplaki E, Yuan N, Zanchettin D, Zhang H, Zerefos C (2016) European summer temperatures since roman times. Environ Res Lett 11(2016):024001

Luterbacher J, Pfister C (2015) The year without a summer. Nat Geosci 8:246-248. https://doi.org/10.1038/ngeo2404

Luterbacher J, Rickli R, Xoplaki E, Tinguely C, Beck C, Pfister C, Wanner H (2001) The Late Maunder Minimum (1675-1715)—a key period for studying decadal scale climatic change in Europe. Clim Change 49:441-462. https://doi.org/10.1023/A:1010667524 422

Luterbacher J, Xoplaki E, Dietrich D, Jones PD, Davies TD, Portis D, Gonzalez-Rouco JF, von Storch H, Gyalistras D, Casty D, Wanner H (2002) Extending North Atlantic Oscillation reconstructions back to 1500. Atmos Sci Lett 2:114-124. https://doi.org/10.1006/ asle.2002.0047 
Luterbacher J, Dietrich D, Xoplaki E, Grosjean M, Wanner H (2004) European seasonal and annual temperature variability, trends, and extremes since 1500. Science 303:1499-1503. https://doi. org/10.1126/science.1093877

Mellado-Cano J, Barriopedro D, García-Herrera R, Trigo RM, AlvarezCastro MC (2018) Euro-Atlantic atmospheric circulation during the Late Maunder Minimum. J Clim 31:3849-3863. https://doi. org/10.1175/JCLI-D-17-0261.1

Mellado-Cano J, Barriopedro D, García-Herrera R, Trigo RM, Hernandez A (2019) Examining the North Atlantic Oscillation, East Atlantic pattern and jet variability since 1685 . J Clim. https://doi. org/10.1175/JCLI-D-19-0135.1

Neely III RR, Schmidt A (2016) VolcanEESM: global volcanic sulphur dioxide (SO2) emissions database from 1850 to present-Version 1.0. Centre for Environmental Data Analysis, 04 February 2016. https://doi.org/10.5285/76ebdc0b-0eed-4f70-b89e-55e606bcd568

Ordonez P, Gallego D, Ribera P, Pena-Ortiz C, García-Herrera R (2016) Tracking the Indian Summer Monsoon onset back to the pre-instrumental period. J Clim. https://doi.org/10.1175/ jcli-d-15-0788.1

Paik S, Min S (2018) Assessing the impact of volcanic eruptions on climate extremes using CMIP5 models. J Clim 31:5333-5349. https://doi.org/10.1175/JCLI-D-17-0651.1

Pauling A, Luterbacher J, Casty C, Wanner H (2006) Five hundred years of gridded high-resolution precipitation reconstructions over Europe and the connection to large-scale circulation. Clim Dyn 26:387-405. https://doi.org/10.1007/s00382-005-0090-8

Pinto JG, Raible CC (2012) Past and recent changes in the North Atlantic Oscillation. Wiley Interdiscip Rev Clim Change 3:79-90. https ://doi.org/10.1002/wcc.150

Raible CC, Brönnimann S, Auchmann R, Brohan P, Frölicher TL, Graf H, Jones P, Luterbacher J, Muthers S, Neukom R, Robock A, Self S, Sudrajat A, Timmreck C, Wegmann M (2016) Tambora 1815 as a test case for high impact volcanic eruptions: earth system effects. WIREs Clim Change 7:569-589. https://doi.org/10.1002/wcc.407

Rao MP, Cook BI, Cook ER, D’Arrigo RD, Krusic PJ, Anchukaitis KJ, LeGrande AN, Buckley BM, Davi NK, Leland C, Griffin KL (2017) European and Mediterranean hydroclimate responses to tropical volcanic forcing over the last millennium: volcanism and European hydroclimate. Geophys Res Lett. https://doi. org/10.1002/2017GL073057

Robock A (2000) Volcanic eruptions and climate. Rev Geo Phys 38:191-219

Schamm K, Ziese M, Becker A, Finger P, Meyer-Christoffer A, Schneider U, Schröder M, Stender P (2014) Global gridded precipitation over land: a description of the new GPCC first guess daily product. Earth Syst Sci Data 6:49-60. https://doi.org/10.5194/ essd-6-49-2014

Schwarz G (1978) Estimating the dimension of a model. Ann Stat 6(2):461-464. https://doi.org/10.1214/aos/1176344136

Sigl M, Winstrup M, McConnell JR, Welten KC, Plunkett G, Ludlow F, Büntgen U, Caffee M, Chellman N, Dhal-Jensen D, Fischer H, Kipfstuhl S, Kostick C, Maselli OJ, Mekhaldi F, Mulvaney R, Muscheler R, Pasteris DR, Pilcher JR, Salzer M, Schüpbach S, Steffensen JP, Vinther BM, Woodruff TE (2015) Timing and climate forcing of volcanic eruptions for the past 2,500 years. Nature 523:543-549
Slonosky VC, Jones PD, Davies TD (2001) Instrumental pressure observations and atmospheric circulation from the 17th and 18th centuries: London and Paris

Timmreck C (2012) Modeling the climatic effects of large explosive volcanic eruptions. WIREs Clim Change 3:545-564. https://doi. org/10.1002/wcc. 192

Toohey M, Sigl M (2017) Volcanic stratospheric sulfur injections and aerosol optical depth from 500 BCE to 1900 CE. Earth Syst Sci Data 9:809-831. https://doi.org/10.5194/essd-9-809-2017

Trigo RM, Osborn TJ, Corte-Real JM (2002) The North Atlantic Oscillation influence on Europe: climate impacts and associated physical mechanisms. Clim Res 20:9-17. https://doi.org/10.3354/ cr020009

Trigo RM, Vaquero JM, Alcoforado MJ, Barriendos M, Taborda J, García-Herrera R, Luterbacher J (2009) Iberia in 1816, the year without a summer. Int J Climatol 29:99-115. https://doi. org/10.1002/joc. 1693

Vautard R, Yiou P (2009) Control of recent European surface climate change by atmospheric flow. Geophys Res Lett 36:L22702. https ://doi.org/10.1029/2009GL040480

Vega I, Gallego D, Ribera P, de Paula Gómez-Delgado F, García-Herrera R, Peña-Ortiz C (2018) Reconstructing the Western North Pacific Summer Monsoon since the late nineteenth century. J Clim 31:355-368. https://doi.org/10.1175/JCLI-D-17-0336.1

Vicente-Serrano SM, López-Moreno JI (2008) Nonstationary influence of the North Atlantic Oscillation on European precipitation. $\mathrm{J}$ Geophys Res 113:D20120. https://doi.org/10.1029/2008JD010382

Vicente-Serrano S, García-Herrera R, Barriopedro D, Azorin-Molina C, Lopez-Moreno JI, Martín-Hernández N, Tomás-Burguera M, Gimeno L, Nieto R (2015) The Westerly Index as complementary indicator of the North Atlantic oscillation in explaining drought variability across Europe. Clim Dyn. https://doi.org/10.1007/ s00382-015-2875-8

Wallace JM, Gutzler DL (1981) Teleconnections in the geopotential height field during the Northern Hemisphere Winter. Mon Weather Rev 109:784-812

Wegmann M, Brönnimann S, Bhend J, Franke J, Folini D, Wild M, Luterbacher J (2014) Volcanic influence on European summer precipitation through monsoons: possible cause for "years without summer". J Clim 27:3683-3691. https://doi.org/10.1175/JCLID-13-00524.1

Wheeler D, Garcia-Herrera R, Wilkinson CW, Ward C (2009) Atmospheric circulation and storminess derived from Royal Navy logbooks: 1685 to 1750. Clim Change 101:257-280. https://doi. org/10.1007/s10584-009-9732-x

Wilks DS (2006) Statistical methods in the atmospheric sciences, 2nd edn. Elsevier, Oxford, p 627

Woollings T, Hannachi A, Hoskins B (2010) Variability of the North Atlantic eddy-driven jet stream. Q J R Meteorol Soc 649:856-868

Yozgatligil C, Yazici C (2015) Comparison of homogeneity tests for temperature using a simulation study: comparison of homogeneity tests. Int J Climatol. https://doi.org/10.1002/joc.4329

Publisher's Note Springer Nature remains neutral with regard to jurisdictional claims in published maps and institutional affiliations. 